\title{
Pyrolysis of wood pellet in the presence of oxygen carriers in a fluidised bed coupled with a DBD reactor for tar quantification
}

\author{
Yaoyao Zheng*1, Rob Grant ${ }^{2}$, Wenting Hu${ }^{1,3}$ and Stuart A. Scott ${ }^{1}$ \\ ${ }^{1}$ Department of Engineering, University of Cambridge, Trumpington Street, Cambridge, CB2 \\ IPZ, United Kingdom. \\ ${ }^{2}$ Gas Recovery \& Recycle Ltd, Aztec House, Perrywood Business Park, Salfords, Surrey, RH1 5DZ, \\ United Kingdom \\ ${ }^{3}$ School of Engineering, Newcastle University, Newcastle upon Tyne, NE1 7RU, United \\ Kingdom \\ *Corresponding Author: yz450@ cam.ac.uk
}

\begin{abstract}
The pyrolysis of wood in the presence of chemical looping agents including $\mathrm{Fe}_{2} \mathrm{O}_{3}$, mayenite-supported $\mathrm{CuO}$ and mayenite-supported $\mathrm{Cu}_{2} \mathrm{O}$ was studied from 773 to $1173 \mathrm{~K}$. A continuous tar quantification system, based on a DBD reactor downstream of the fluidised bed, was developed to allow quantification of the tar formed. An oxygen-containing plasma was used to convert volatiles and tars to measurable carbon-containing species, mainly $\mathrm{CO}, \mathrm{CH}_{4}$, and $\mathrm{CO}_{2}$. It was found that pyrolysis of the wood in alumina sand produced $\mathrm{CH}_{4}, \mathrm{CO}, \mathrm{CO}_{2}$, tar and char as the main products. Tar cracking was observed above $1073 \mathrm{~K}$, and this mainly generated $\mathrm{CH}_{4}$. Both $\mathrm{Fe}_{2} \mathrm{O}_{3}$ and mayenite-supported $\mathrm{Cu}$-based oxides were effective for in situ combustion of the pyrolysis products, particularly tar, at temperatures exceeding $873 \mathrm{~K}$. Mayenite-supported $\mathrm{CuO}$ showed the highest reactivity. The results showed the potential of using metal oxides for direct combustion of biomass, and particularly converting the tarry products during devolatisation. The better activity of mayenite-supported $\mathrm{CuO}$ compared to $\mathrm{Fe}_{2} \mathrm{O}_{3}$ and $\mathrm{Cu}_{2} \mathrm{O}$ in these experiments was mainly due to the ability of $\mathrm{CuO}$ to release gaseous oxygen at higher temperatures.
\end{abstract}

Keywords: biomass, chemical looping combustion, DBD reactor, online tar quantification, $\mathrm{Fe}_{2} \mathrm{O}_{3}$, mayenite-supported $\mathrm{CuO}$. 


\section{Introduction}

Chemical looping combustion (CLC) is a way of combusting a fuel using oxygen supplied from a solid metal oxide (commonly referred to as an oxygen carrier) and produces $\mathrm{CO}_{2}$, undiluted by nitrogen. Oxygen carriers are typically transition metal oxides able to give up oxygen by reduction whilst oxidising a fuel (in a fuel reactor). The reduced oxides are regenerated by air (in an air reactor), which allows the oxygen carriers to be used in the next combustion cycle. The reactions are:

Fuel reactor: $\left(n+\frac{m}{2}\right) \mathrm{Mtl}_{x} \mathrm{O}_{y}+\mathrm{C}_{n} \mathrm{H}_{2 m} \rightarrow\left(n+\frac{m}{2}\right) \mathrm{Mtl}_{x} \mathrm{O}_{y-2}+n \mathrm{CO}_{2}+m \mathrm{H}_{2} \mathrm{O}$

Air reactor: $\mathrm{Mtl}_{x} \mathrm{O}_{y-2}+\mathrm{O}_{2} \rightarrow \mathrm{Mtl}_{x} \mathrm{O}_{y}$

where Mtl represents some transition metal. The implication of CLC is that it avoids the mixing of $\mathrm{CO}_{2}$ produced with a large proportion of $\mathrm{N}_{2}$ (normally the fuel is combusted in air). This saves the energy that would have been required to separate the $\mathrm{CO}_{2}$ and $\mathrm{N}_{2}$ for carbon capture.

The CLC of fuels has been widely studied with both naturally occurring oxide minerals (such as ilmenite) and synthetic oxygen carriers, which usually consist of $\mathrm{Fe}, \mathrm{Ni}, \mathrm{Mn}, \mathrm{Cu}$, either used on their own or supported on inert materials such as $\mathrm{Al}_{2} \mathrm{O}_{3}, \mathrm{ZrO}_{2}, \mathrm{MgAl}_{2} \mathrm{O}_{4}$ [1-8]. Among these materials, oxides of $\mathrm{Mn}$ and $\mathrm{Cu}$ have the ability to release gaseous oxygen at high temperatures, known as chemical looping oxygen uncoupling (CLOU). CLC was initially applied to gaseous fuels. According to reaction $\mathrm{R}-1$, the oxygen carriers convert the gaseous fuel to $\mathrm{CO}_{2}$ and $\mathrm{H}_{2} \mathrm{O}$. For a solid fuel, e.g. coal- or biomassderived char, it is unlikely to occur through a direct solid-solid reaction. Thus, application of CLC to solid fuels either uses CLOU materials or converts the solid fuels into gaseous fuels by gasification (either in- or $e x-s i t u$ ). Liquid fuels such as tar have been studied only recently, normally based on model compounds due to the complexity of tar. Mendiara et al. [9] investigated the removal of toluene by selective reforming in a chemical looping system (in TGA and a lab-scale fixed bed reactor), using four oxygen carriers $\left(\mathrm{NiO} / \mathrm{MgAl}_{2} \mathrm{O}_{4}, \mathrm{NiO} / \mathrm{NiAl}_{2} \mathrm{O}_{4}, \mathrm{Mn}_{3} \mathrm{O}_{4} / \mathrm{Mg}-\mathrm{ZrO}_{2}\right.$, and $\left.\mathrm{FeTiO}_{3}\right)$. Their study compared the extent of carbon deposition of toluene on the four oxygen carriers and found that the addition of water reduced carbon deposition. Ryden et al. [10] investigated CLC of kerosene with Ni-, Mn-, Cuand Fe-based oxygen carriers in continuous operation. They reported 95\% - 99\% conversion of carbon 
in the fuel to $\mathrm{CO}_{2}$. Biomass has been studied extensively in CLC systems [11-13]. Zeng et al. [13] proposed a chemical looping pyrolysis-gasification system for syngas production with a two-zone fuel reactor; in the first zone the biomass was pyrolysed and in the second zone steam was introduced to gasify the char and convert the pyrolysis products to give high $\mathrm{H}_{2} / \mathrm{CO}$ ratio syngas. In a chemical looping system (or indeed any thermochemical conversion), the biomass fuel will first be heated and release volatile matter. This volatile matter represents a large proportion of the calorific value of the fuel, and if unconverted, the higher molecular mass species can condense as "tars" which can adversely affect down-stream equipment. The primary volatile components often undergo secondary reactions, either forming lighter species and being cracked to carbon, or forming larger species. The presence of solids in a reactor can have a profound effect on the fate of the volatiles and the formation of tars. Tars have often been a problem during gasification of biomass, and interaction with solids has been proposed as a way of converting these tars to lighter species, either in the primary gasification reactor, or by processing the gas downstream, e.g. the use of dolomite or catalytically active minerals such as olivine, nickel catalysts etc. [14]. In a chemical looping system, the volatiles are immediately exposed to solids which can react with them, potentially leading to a much more efficient combustion of the volatiles. Sarvaramini and Larachi [15] have studied CLC of biomass volatiles that came from torrefaction at $300^{\circ} \mathrm{C}$. They found up to $99 \%$ of the carbon released from birch wood torrefaction was converted to $\mathrm{CO}_{2}$ by $\mathrm{Fe}_{2} \mathrm{O}_{3}$ in a fixed bed reactor at $600^{\circ} \mathrm{C}$. However, the effectiveness of different solids for the conversion of the volatiles still requires further investigation, partly owing to the difficulties in measuring the volatiles or "tars" produced during experiments.

Measurement of tar content is challenging and usually done in a continuous system, from which the tars can be collected for a reasonable period, before being analysed off-line. This analysis can either be gravimetric [16] or based on other methods such as GC/MS to identify the complex mix of species [17]. This leads to a difference in the definition of tar, depending on how the tar is collected. Reported tar collection methods include the IEA tar measurement protocol (where six chemical solvents and water/ice bath are used for), the dust and tar measurement method (which aims to measure dust and tar from heavily polluted gases at the same time) etc. [17]. These methods require multiple stages, 
involving the use of chemicals and heating/cooling treatment of the gas line, and usually need a considerable amount of time. Nunes et al. [18] adopted a simpler approach for tar collection in the investigation of tar formation and destruction in a fixed bed reactor from biomass fuels: a tar trap tube, which was immersed in liquid $\mathrm{N}_{2}$, was attached to the main reactor for the condensation of tar from upstream. The tar trap was then washed offline with a mixture of methanol and chloroform for further analysis. In batch experiments, measurements of tar are difficult owing to the rapid release of volatiles and the difficulty of collecting sufficient amounts for analysis. Chern [19] attempted to solve this problem by using a multiport valve with loops to rapidly collect gas samples and store them for later GC analysis. This allowed speciation, but it was laborious.

In this study, the effectiveness of typical chemical looping agents: $\mathrm{Fe}_{2} \mathrm{O}_{3}, \mathrm{CuO}$ and $\mathrm{Cu}_{2} \mathrm{O}$ (both $\mathrm{CuO}$ and $\mathrm{Cu}_{2} \mathrm{O}$ were supported on mayenite), for the conversion of volatile matter is investigated. The effect of the oxygen carriers on the product distribution of a batch pyrolysis of biomass in a fluidised bed were studied and compared with that achieved in a nominally 'inert' bed of alumina sand. Both types of oxygen carriers have been investigated for chemical looping combustion. Copper oxide differs from the other two, in that it can release gas phase oxygen at chemical looping temperatures; this effect has been proposed as method of improving the conversion of gaseous and solid fuels (i.e. CLOU combustion [20]).

To enable online quantification of the unconverted volatile matter (referred to as "tar" here), an oxygencontaining dielectric barrier discharge (DBD) plasma reactor was used to convert the tar produced from the fluidised bed to lighter detectable species (mostly $\mathrm{CO}_{2}$ and $\mathrm{CO}$ ), enabling the quantification of the carbon in the tar. DBD plasma reactors have been widely studied for the abatement of volatile organic compounds (VOCs) [21-24]. The excited species in the plasma (here a plasma containing $\mathrm{O}_{2}$ and $\mathrm{O}-$ containing exited species) can oxidise and crack hydrocarbons to detectable species. By comparing the amounts of detectable species when the gas has been treated with plasma with when it has not, an estimate of the carbon contained within the volatile species can be made. Owing to the placement of the trap at $0^{\circ} \mathrm{C}$, this "tar" that consists of all the carbon-containing species would have condensed from the analysed gas. This differs from the IEA tar measurement protocol, but is similar to the method used 
by Nunes et al. [18]. Of course, this relies on assumption that all of the higher molecular mass components are completely converted to detectable species, which has been evaluated by the overall carbon balance in the experiments.

\section{Experimental}

\subsection{Experimental setup}

The experimental setup consisted of a fluidised bed reactor, a DBD plasma reactor and a chilled trap before a train of gas analysers, as shown in Fig. 1. The fluidised bed reactor was a quartz tube (i.d. 29 $\mathrm{mm}$, o.d. $32 \mathrm{~mm}$ ), with a porous distributor positioned $110 \mathrm{~mm}$ above the gas inlet at the bottom. The sampled gas from the fluidised bed mixed with a stream of air prior to passing through the DBD reactor. All flows were metered and controlled via variable area flow meters equipped with valves. The DBD reactor and the sampling line connecting it to the fluidised bed were externally heated (refer to 2.4.1 for operating temperatures) by heating tapes (Omega, STH051). The stream leaving the DBD reactor was passed through a trap immersed in ice water and consisting of a tube packed with $\mathrm{CaCl}_{2}$ and ceramic beads, and plugged with glass wool at each end to remove tar, water and carbon fines, before the gases were analysed by Fourier transform infrared spectroscopy (FTIR) (ThermoFisher Scientific, NICOLET iS10) and a paramagnetic oxygen analyser (ABB, EL3020) positioned after the FTIR. The configuration of the DBD reactor is shown in Fig. 2. It consisted of two metal electrodes, with the high voltage electrode being a stainless-steel rod (diameter of $25.0 \mathrm{~mm}$, length of $80 \mathrm{~mm}$ ) and the ground electrode being a stainless-steel tube (i.d. $36.0 \mathrm{~mm}$ ). A quartz tube (i.d. $26.0 \mathrm{~mm}$, o.d. $30.0 \mathrm{~mm}$ ) covering the high voltage electrode was used as the dielectric barrier, leaving a gap $(3.0 \mathrm{~mm})$ between the outer surface of the quartz tube and the inner surface of the ground electrode for the plasma discharge and to allow the sampled gas to flow through. The DBD reactor was sealed by two Teflon end-caps, which also provided electrical insulation and support for the electrodes. Alternating voltage ranging from 13.2 to $15.2 \mathrm{kV}$ (peak to peak) at a frequency of $\sim 22 \mathrm{kHz}$ was supplied to generate plasma via a plasma generator (PVM500-2500, Information Unlimited). 


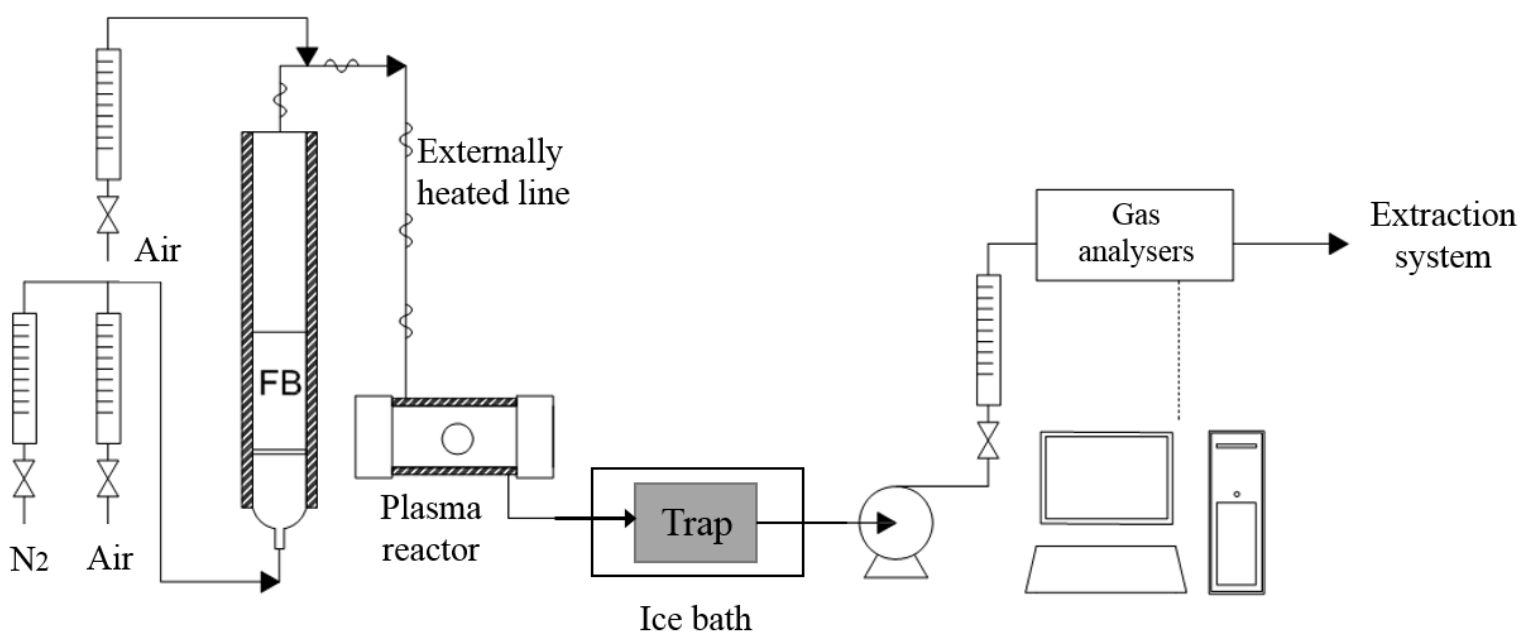

Figure 1 Process flow diagram of the experimental set-up.

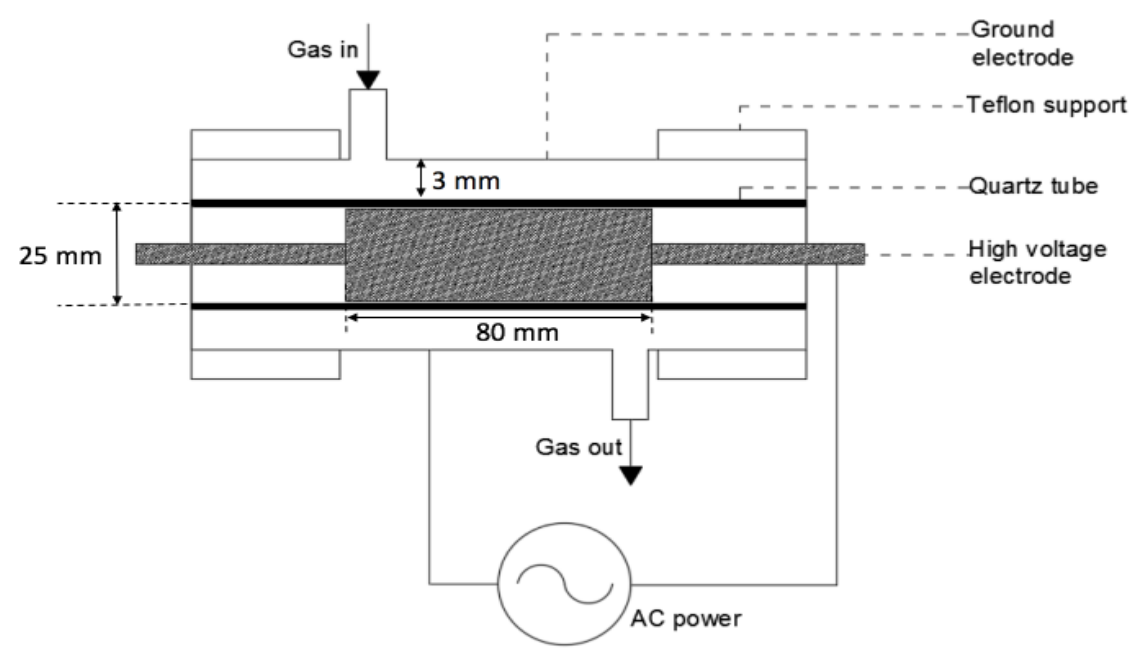

Figure 2 Configuration of the downstream plasma reactor.

\subsection{Materials}

\subsubsection{Wood pellets}

The received wood pellets were crushed to $4.0-4.2 \mathrm{~mm}$. They were air dried at ambient environment for 24 hours prior to being fed into the fluidised bed. The results of elemental analysis and proximate analysis of the wood sample are shown in Tables 1 and 2.

Table 1 Elemental analysis (air dried). 


\begin{tabular}{|c|c|}
\hline Element & Mass \% \\
\hline Carbon & 46.33 \\
\hline Hydrogen & 6.12 \\
\hline Nitrogen & 0.00 \\
\hline Oxygen (balanced) & 47.55 \\
\hline
\end{tabular}

Table 2 Proximate analysis (air dried).

\begin{tabular}{|c|c|}
\hline Composition & Mass \% \\
\hline Moisture & 8.53 \\
\hline Volatile matter & 75.21 \\
\hline Fixed carbon & 15.83 \\
\hline Ash & 0.42 \\
\hline
\end{tabular}

\subsubsection{Materials used as the fluidised bed}

Here, the fluidised bed consisted of particles (sieve size of $355-425 \mu \mathrm{m}$ ) of alumina sand, $\mathrm{Fe}_{2} \mathrm{O}_{3}$, mayenite-supported $\mathrm{CuO}$ or $\mathrm{Cu}_{2} \mathrm{O}$. The alumina sand was sieved, and washed in de-ionised (DI) water, followed by drying at $393 \mathrm{~K}$ for 24 hours prior to use. The bulk density of alumina sand was 2200 $\mathrm{kg} / \mathrm{m}^{3}$. The voidage of the alumina sand, 0.44 , was measured by filling a packed bed of alumina sand of water just to the surface and recording the volume of water added, giving a particle density of 3930 $\mathrm{kg} / \mathrm{m}^{3} . \mathrm{Fe}_{2} \mathrm{O}_{3}$ was prepared from iron oxide powers (Fisher Scientific; mean diameter of $10 \mu \mathrm{m}$ with purity $>95 \mathrm{wt} \%$ ). Iron oxide powder was granulated using DI water, with a mass ratio of iron oxide powder to DI water of 10:1. The mixing was carried out in a commercial mixer. The resulting granules were sieved to 355 to $600 \mu \mathrm{m}$, followed by the calcination of the agglomerated particles at $1273 \mathrm{~K}$ for 6 hours in air. The $\mathrm{Fe}_{2} \mathrm{O}_{3}$ particles were then crushed and sieved to $355-425 \mu \mathrm{m}$, giving a bulk density of $1760 \mathrm{~kg} / \mathrm{m}^{3}$. The estimated particle density of $\mathrm{Fe}_{2} \mathrm{O}_{3}$, assuming the particles formed a close-packed bed with a voidage of $\sim 0.40[25,26]$ was $2930 \mathrm{~kg} / \mathrm{m}^{3}$. The preparation of mayenite-supported $\mathrm{CuO}$ followed the method described in Ref. [27]. The support, mayenite, helped to increase the mechanical strength and prevent deactivation of $\mathrm{CuO}$ in a fluidising environment and at high temperatures. The 
particles had a composition of $60 \mathrm{wt} \% \mathrm{CuO}, 23 \mathrm{wt} \% \mathrm{Al}_{2} \mathrm{O}_{3}$ and $17 \mathrm{wt} \% \mathrm{CaO}$. Similarly, based on a voidage of $\sim 0.40$ of mayenite-supported $\mathrm{CuO}$, and a measured bulk density of $1200 \mathrm{~kg} / \mathrm{m}^{3}$, an estimated particle density of $2000 \mathrm{~kg} / \mathrm{m}^{3}$ was obtained for mayenite-supported $\mathrm{CuO}$.

Mayenite-supported $\mathrm{Cu}_{2} \mathrm{O}$ was prepared from the mayenite-supported $\mathrm{CuO}$ by fluidising in a bed of $\mathrm{N}_{2}$ at $1173 \mathrm{~K}$ until no oxygen was detected. When fluidised in $\mathrm{N}_{2}, \mathrm{CuO}$ decomposed to $\mathrm{Cu}_{2} \mathrm{O}$; further decomposition to $\mathrm{Cu}$ was avoided either by its own equilibrium with the trace amount of $\mathrm{O}_{2}$ with the ambient and/or the slow reaction kinetics. To ensure consistency, a single batch of mayenite-supported $\mathrm{Cu}_{2} \mathrm{O}$ was prepared and divided equally between experiments.

\subsubsection{Characterisation of the oxygen carriers}

$\mathrm{X}$-ray diffraction (XRD) analysis of the oxygen carriers were performed using an Empyrean PANalytical diffractometer $(\mathrm{Cu} \mathrm{K}$ radiation with a voltage of $40 \mathrm{kV}$ and current of $40 \mathrm{~mA})$ with a scan range from $5^{\circ}$ to $80^{\circ}$ in $2 \theta$ and step size of $0.0167^{\circ}$. The diffractograms obtained were compared with references from Inorganic Crystal Structure Database (ICSD) for phase identification.

\subsection{Plasma SED measurement}

Specific energy density (SED) was used to characterise the density of plasma energy within the downstream plasma reactor and is given by

$$
S E D=\frac{P}{Q},
$$

where $P$ is the power input $(\mathrm{W}), Q$ is the gas flow rate $(\mathrm{L} / \mathrm{s})$ (all the flow rates here are expressed at 293 $\mathrm{K}$ and $1 \mathrm{~atm}$ ) passed through the reactor. The power input is related to the frequency $f$ of the AC supply by:

$$
P=E \times f
$$

The energy input per cycle $E$ is [28], 


$$
E=\int_{0}^{t} V(t) I(t) d t=\int_{0}^{t} V(t) d q
$$

where $V(t)$ is the voltage, $I(t)$ is the current and $q$ is the charge. Thus, the power can be determined from the $V$ - $q$ Lissajous diagram. The voltage was measured using a high voltage probe (TESTEC, 1000:1, $30 \mathrm{kV}, 50 \mathrm{MHz}$ ) with the sensing head connected to the high voltage electrode. The charge was obtained from the voltage (Tektronix probe, P6015A, 1:1) across a $1 \mu \mathrm{F}$ capacitor, connected in series between the reactor ground electrode and earth. Both the voltage and charge signals were collected simultaneously using an oscilloscope (Tektronix, TDS 3012) in X-Y mode. A typical $V-q$ Lissajous curve is presented in Fig. S1 (refer to Supplementary materials S1).

\subsection{Operating conditions and tar measurement}

\subsubsection{Operating conditions}

The fluidised bed was loaded with $\sim 20 \mathrm{ml}$ of bed material (i.e. alumina sand, $\mathrm{Fe}_{2} \mathrm{O}_{3}$, mayenitesupported $\mathrm{CuO}$, or mayenite-supported $\mathrm{Cu}_{2} \mathrm{O}$ ), and fluidised by pure $\mathrm{N}_{2}$ with a flow rate of $\sim 3 \mathrm{~L} / \mathrm{min}$. The temperature of the bed was varied from 773 to $1173 \mathrm{~K}$, giving the ratio of superficial velocity to minimum fluidising velocity $U / U_{\mathrm{mf}}$ of: 1.7 to 3.4 in alumina sand; 3.0 to 5.8 in mayenite-supported $\mathrm{CuO} ; 3.0$ to 6.0 in mayenite-supported $\mathrm{Cu}_{2} \mathrm{O} ; 2.0$ to 4.0 in $\mathrm{Fe}_{2} \mathrm{O}_{3}$. The value of $U_{\mathrm{mf}}$ was calculated using the correlation of Wen and $\mathrm{Yu}$ [29]. The air stream entering the sampling line was set to $\sim 0.45 \mathrm{~L} / \mathrm{min}$, and the total flow rate of the sampling line was set to $0.90 \mathrm{~L} / \mathrm{min}$. The temperature of the sampling line was kept at $573 \mathrm{~K}$ and the plasma reactor at $523 \mathrm{~K}$. After each experiment, the fluidising gas was switched from $\mathrm{N}_{2}$ to air to burn off any char remaining in the fluidised bed; and the amount of $\mathrm{CO}$ and $\mathrm{CO}_{2}$ from the burn-off was measured to determine the yield of char. For every experiment, $0.0538 \pm$ $0.0002 \mathrm{~g}$ of wood was fed. Sufficient bed material was provided in each batch experiment for full conversion of the carbon content in wood to $\mathrm{CO}_{2}$, assuming $\mathrm{Fe}_{2} \mathrm{O}_{3}$ was reduced to $\mathrm{Fe}_{3} \mathrm{O}_{4}, \mathrm{CuO}$ to $\mathrm{Cu}_{2} \mathrm{O}$, and $\mathrm{Cu}_{2} \mathrm{O}$ to $\mathrm{Cu}$. The duration of the experiment was set to be equal to the pyrolysis time for the fuel, assuming that this can be determined by noting when $\mathrm{CH}_{4}$ was no longer detected. Each experiment was repeated three times. 


\subsubsection{Tar/volatile quantification}

A method to allow the online quantification of the total amount of carbon in the tar was developed; whilst the composition of the tar can be of interest, it is beyond the scope of the current study. In the current study, to measure the carbon in the tar produced at one experimental condition, two identical experiments were required, one with plasma and the other without. To have identical experimental conditions, the wood mass, flow rate, $\mathrm{N}_{2}$ to air ratio of the two experiments need to be strictly controlled. The difference in the signals from FTIR between experiments, one with the plasma on and the other off was, analysed (i.e. two separate experiments were carried out with other conditions being the same). In the first experiment without the plasma, the sampled gas passes through the sample line and heavy molecular mass species are condensed in the tar trap. In the second, identical experiment, the gases pass through the active plasma reactor, and are converted and oxidized (via the added air) to smaller and detectable carbon-containing species.

Tar is a complex mixture of condensable hydrocarbons; here, for simplicity, tar was defined as any carbon-containing gaseous species, except $\mathrm{CO}, \mathrm{CO}_{2}$ and $\mathrm{CH}_{4}$, that was unable to pass through the tar trap un-converted. This definition means that other light hydrocarbons, not condensed at $0^{\circ} \mathrm{C}$ are also included in the "tar" measurement. If quantified by the FTIR, it would be possible to correct for these lighter carbon-containing species, since they are detectable. However, in the experiments performed here, as shown in Fig. 5 for example, the gas after the tar trap (even with no plasma active) contained only trace amounts of other carbon-containing species, predominantly traces of acetic acid. In these experiments, it would appear that, other than $\mathrm{CH}_{4}, \mathrm{CO}$, and $\mathrm{CO}_{2}$, most of the remaining carbon in the volatile matter was contained within species which condensed at $0^{\circ} \mathrm{C}$, i.e. tarry species.

Assuming that tar can be converted to $\mathrm{CO}, \mathrm{CH}_{4}$ and $\mathrm{CO}_{2}$ completely, the amount of carbon in the tar entering the sampling system is given by:

$$
m_{\mathrm{C}, \mathrm{tar}}=\sum_{i=\mathrm{CO}_{\mathrm{CO}}} \text { or } \mathrm{CH}_{4} m_{i}^{\text {on }}-\sum_{i=\mathrm{CO}_{2} \mathrm{CO}_{2} \text { or } \mathrm{CH}_{4}} m_{i}^{\text {off }}
$$

where $m_{i}^{\text {on }}$ and $m_{i}^{\text {off }}$ are the masses of carbon in the carbon-containing species $i\left(\mathrm{CO}, \mathrm{CO}_{2}\right.$ or $\left.\mathrm{CH}_{4}\right)$ that entered the sampling system for the separate experiments with the plasma on and off, respectively. 
Here, $m_{i}^{\text {on }}$ and $m_{i}^{\text {off }}$ were determined by taking the integral of the rate of species $i$ that entered the sampling system and detected by FTIR, $R_{i}(t)$, over pyrolysis time from $t_{0}$ to $t_{a}$ :

$$
m_{i}=\int_{t_{0}}^{t_{a}} R_{i}(t) d t
$$

The above equation gives the mass of carbon entering the sampling system over the duration of an experiment. To obtain the total amount of carbon in each species, for instance in tar, the ratio of the total gas flow rate in the fluidised bed, $F_{F B}$, to the flow rate into to the sampling line $F_{\text {sampling }}$ was used:

$$
M_{\mathrm{C}, \mathrm{tar}}=m_{\mathrm{C}, \operatorname{tar}} \times \frac{F_{\mathrm{FB}}}{F_{\text {sampling }}},
$$

where $M_{\mathrm{C}, \mathrm{tar}}$ is the total amount carbon in the tar produced in the fluidised bed.

Following each experiment, the residual amount of carbon remaining in the bed was measured by burning off using air. The carbon balance was calculated by:

$$
\begin{gathered}
m \%=\frac{\left(\sum_{i} m_{i}^{\text {off }}+m_{\mathrm{C}, \text { burn-off }}+m_{\mathrm{C}, \text { tar }}\right) \times \frac{F_{\mathrm{FB}}}{F_{\mathrm{Sampling}}}}{M_{\mathrm{C}, \text { total }}} \times 100 \%, \\
M_{\mathrm{C}, \text { total }}=M_{\text {wood,total }} \times x_{\mathrm{C}},
\end{gathered}
$$

where $M_{\text {wood,total }}$ is the total mass of wood fed into the fluidised bed, and $x_{\mathrm{C}}$ is the weight fraction of elemental carbon in the wood. $M_{\mathrm{C}, \text { total }}$ is the total carbon content in the wood fed. $m_{\mathrm{C}, \text { burn-off }}$ is the amount of carbon in the char determined by burn-off in air, after pyrolysis time $t_{a}$ :

$$
m_{\mathrm{C}, \mathrm{burn}-\mathrm{off}}=\int_{t_{a}}^{t_{b}} R_{\mathrm{co}, \mathrm{burn}-\mathrm{off}}+R_{\mathrm{co}_{2}, \mathrm{burn}-\mathrm{off}} d t
$$

where $R_{\text {co,burn-off }}$ and $R_{\mathrm{co}_{2} \text {,burn-off }}$ are the rates of production of $\mathrm{CO}$ and $\mathrm{CO}_{2}$ (expressed as equivalent mass of carbon and corrected for dilution in the sampling system) during burn-off from $t_{a}$ to $t_{b}$.

The yield of gaseous species $i, Y_{i}$ is then,

$$
Y_{i}=\frac{m_{(i, \mathrm{off})} \times \frac{F_{\mathrm{FB}}}{F_{\text {sampling }}}}{M_{\mathrm{C}, \text { total }}} .
$$

The yield of $\operatorname{tar} Y_{\operatorname{tar}}$ is 


$$
Y_{\mathrm{tar}}=\frac{M_{\mathrm{C}, \mathrm{tar}}}{M_{\mathrm{C}, \mathrm{total}}}
$$

and the yield of char $Y_{\text {char }}$ is

$$
Y_{\text {char }}=\frac{m_{(\text {C,burn }- \text { off }) \times \frac{F_{\mathrm{FB}}}{F_{\text {sampling }}}}}{M_{\text {C,total }}} .
$$

Additionally, the change in composition of the gases can affect the total flow rate through the sampling line. In particular, the generated tar (without plasma) appeared to block the sampling line, leading to an increased pressure drop and causing a change in the total flow rate through the line. To resolve the issue for the purpose of tar measurement, a correction for the change in flow rate was applied. See S2 in Supplementary materials for the correction of the flow rate.

\section{Results}

\subsection{Characterisation of the oxygen carriers}

XRD analysis of fresh $\mathrm{Fe}_{2} \mathrm{O}_{3}$, mayenite-supported $\mathrm{CuO}$ and $\mathrm{Cu}_{2} \mathrm{O}$ particles were carried out, as shown in Fig. 3. The diffractogram of $\mathrm{Fe}_{2} \mathrm{O}_{3}$ sample showed a predominant $\mathrm{Fe}_{2} \mathrm{O}_{3}$ phase with some unidentified impurities. In mayenite-supported $\mathrm{CuO}$, the dominant phases are $\mathrm{Ca}_{12} \mathrm{Al}_{14} \mathrm{O}_{33}$ (mayenite) and $\mathrm{CuO}$. The diffractogram of mayenite-supported $\mathrm{Cu}_{2} \mathrm{O}$ particles shows that $\mathrm{CuO}$ had mostly been reduced to $\mathrm{Cu}_{2} \mathrm{O}$ (the main peaks of the $\mathrm{CuO}$ phase at $35.59^{\circ}$ and $38.78^{\circ}$ are barely visible) whilst the mayenite phase remained unchanged. 


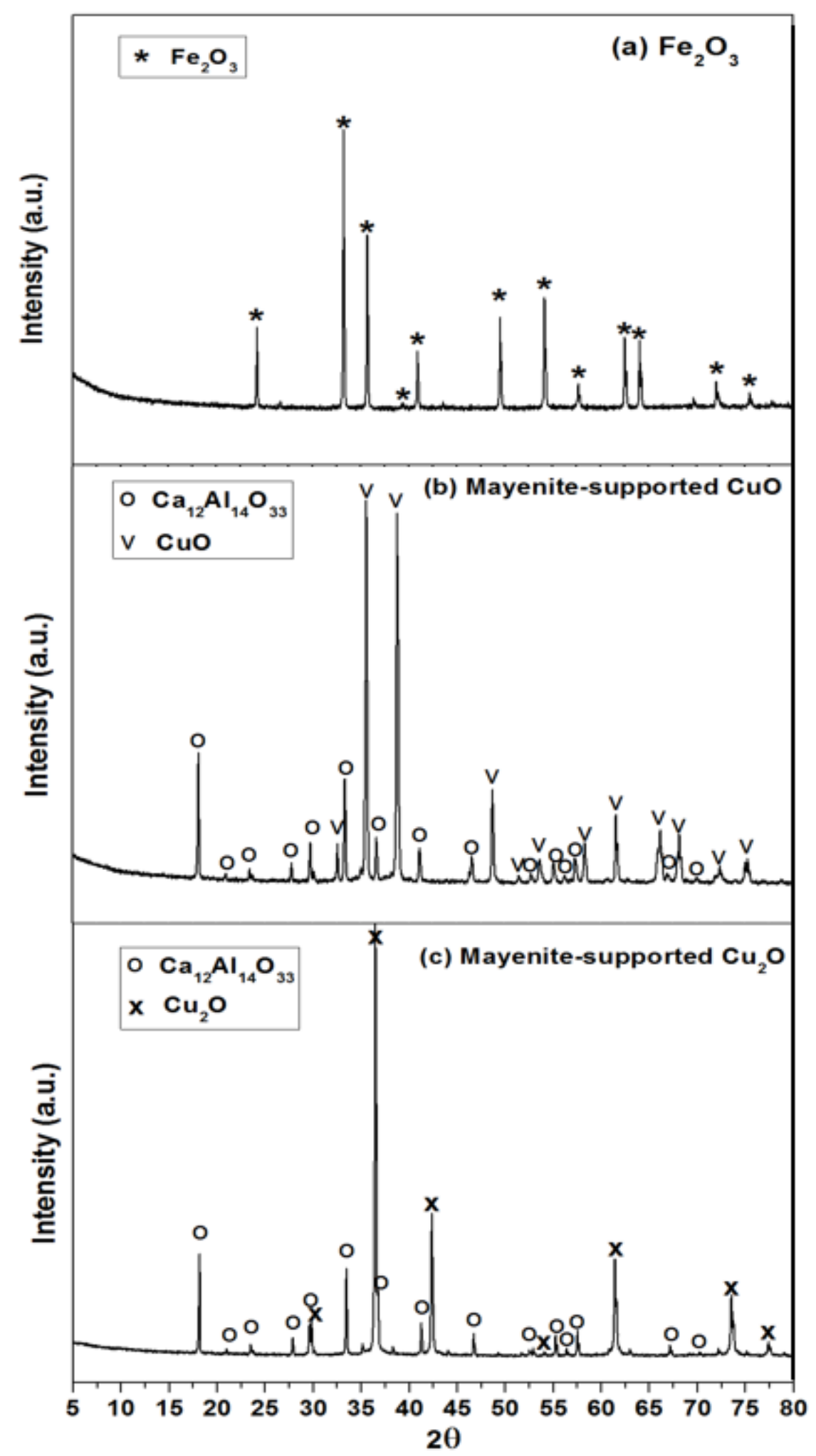

Figure 3 XRD diffractograms of fresh (a) $\mathrm{Fe}_{2} \mathrm{O}_{3}$, (b) mayenite-supported $\mathrm{CuO}$ and (c) mayenitesupported $\mathrm{Cu}_{2} \mathrm{O}$, where the collection codes of the references used from ICSD are 15840 for $\mathrm{Fe}_{2} \mathrm{O}_{3}$, and 241243 for $\mathrm{Ca}_{12} \mathrm{Al}_{14} \mathrm{O}_{33}, 69758$ for $\mathrm{CuO}$, and 172174 for $\mathrm{Cu}_{2} \mathrm{O}$. 


\subsection{Tar measurements}

\subsubsection{Identification of product species}

Figure 4 shows the IR spectra of the gases leaving the DBD reactor in the absence of additional oxygen (denoted by "pure" $\mathrm{N}_{2}$ ) and when air is mixed in to the gases prior to the DBD reactor (giving $~ 8.3$ vol\% oxygen). $\mathrm{N}_{2}$ was used to fluidise a bed of alumina sand in each case. When wood was fed into the fluidised bed, the gas contained species produced from wood pyrolysis. The significant peaks at around $630-710 \mathrm{~cm}^{-1}, 2280-2380 \mathrm{~cm}^{-1}$, and $3580-3770 \mathrm{~cm}^{-1}$ are typical peaks of $\mathrm{CO}_{2}$. The main product measured when the plasma was running in $\mathrm{N}_{2}$ was $\mathrm{CO}_{2}$. The $\mathrm{CO}_{2}$ peaks in $\mathrm{N}_{2}$ might have come from contamination in the system, or have been an artefact of the background subtraction. The FTIR is very sensitive to $\mathrm{CO}_{2}$, so the small peak corresponds to a negligible amount of $\mathrm{CO}_{2}$. When the mixture of $\mathrm{N}_{2}$ and air (i.e. no pyrolysis products) passed through the plasma reactor, the products leaving the plasma reactor were $\mathrm{N}_{2} \mathrm{O}, \mathrm{NO}_{2}, \mathrm{NO}$, and $\mathrm{CO}_{2}$; no clear $\mathrm{CO}$ peak was detected. However, the sensitivity of the FTIR to $\mathrm{CO}$ is much lower than $\mathrm{CO}_{2}$, so detecting any conversion of trace quantities of the $\mathrm{CO}_{2}$ to $\mathrm{CO}$ in the plasma would have been difficult. In Fig. 4, only the main peaks of $\mathrm{N}_{2} \mathrm{O}$ and $\mathrm{NO}$ are marked, because the secondary peaks overlapped those for $\mathrm{CO}, \mathrm{CH}_{4}$ and $\mathrm{CO}_{2}$. Ozone is often formed in plasma reactor in the presence of air [30], but was not observed here. It might be that any ozone produced quickly decomposed in the heated environment and reacted with $\mathrm{N}_{2}$ to form more stable species $\mathrm{NO}$, $\mathrm{N}_{2} \mathrm{O}$ and $\mathrm{NO}_{2}$. This is in agreement with the findings of Huu et al. [24]. They studied methane removal using a plasma-catalytic hybrid reactor, and showed that increasing the temperature of a plasma reactor significantly decreased the ozone concentration in the product stream, e.g. with a clear ozone signal at $303 \mathrm{~K}$ but no signal at $573 \mathrm{~K}$.

With wood fed into the fluidised bed, the pyrolysis products entered the sampling system. A comparison between the spectra with wood fed into fluidised bed with the plasma on (SED of $1027 \mathrm{~J} / \mathrm{L}$ ) and off, is presented in Fig. 5. With the plasma running, the products after the plasma reactor were mainly $\mathrm{N}_{2} \mathrm{O}$, $\mathrm{NO}_{2}, \mathrm{NO}, \mathrm{CO}_{2}, \mathrm{CH}_{4}$ and $\mathrm{CO}$. The main gaseous products from wood pyrolysis without downstream plasma, and having passed through the cold trap, were $\mathrm{CO}, \mathrm{CO}_{2}$, and $\mathrm{CH}_{4}$. Some other absorption peaks at $\sim 950,1700$, and $3050 \mathrm{~cm}^{-1}$ were also observed in Fig. 5, which can be attributed to the peaks of 
acetic acid. There was no significant acetic acid signal after the plasma treatment, suggesting that plasma converted the acetic acid to other species, most likely to $\mathrm{CO}$ or/and $\mathrm{CO}_{2}$. The plasma reactor also seems to have converted some of the $\mathrm{CH}_{4}$, because of the lower intensity of the $\mathrm{CH}_{4}$ signals observed when the sampled stream was subjected to plasma discharge. It should also be remembered that any heavier hydrocarbons that passed through the sampling system unconverted, would have been removed before the FTIR by the cold trap.

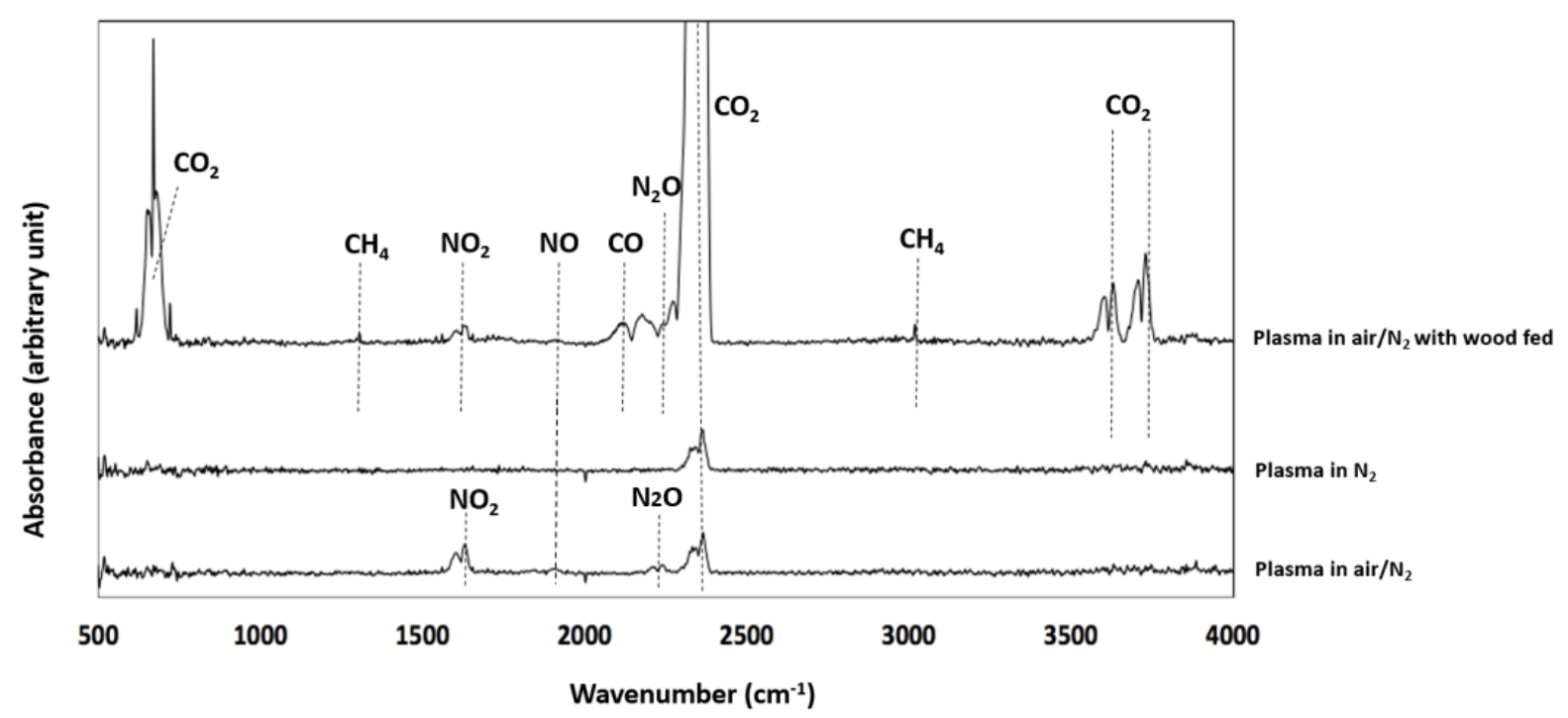

Figure 4 FTIR spectra of species in different gaseous environment in the presence of plasma discharge with fluidised bed loaded with alumina sand and fluidised in $\mathrm{N}_{2}$.

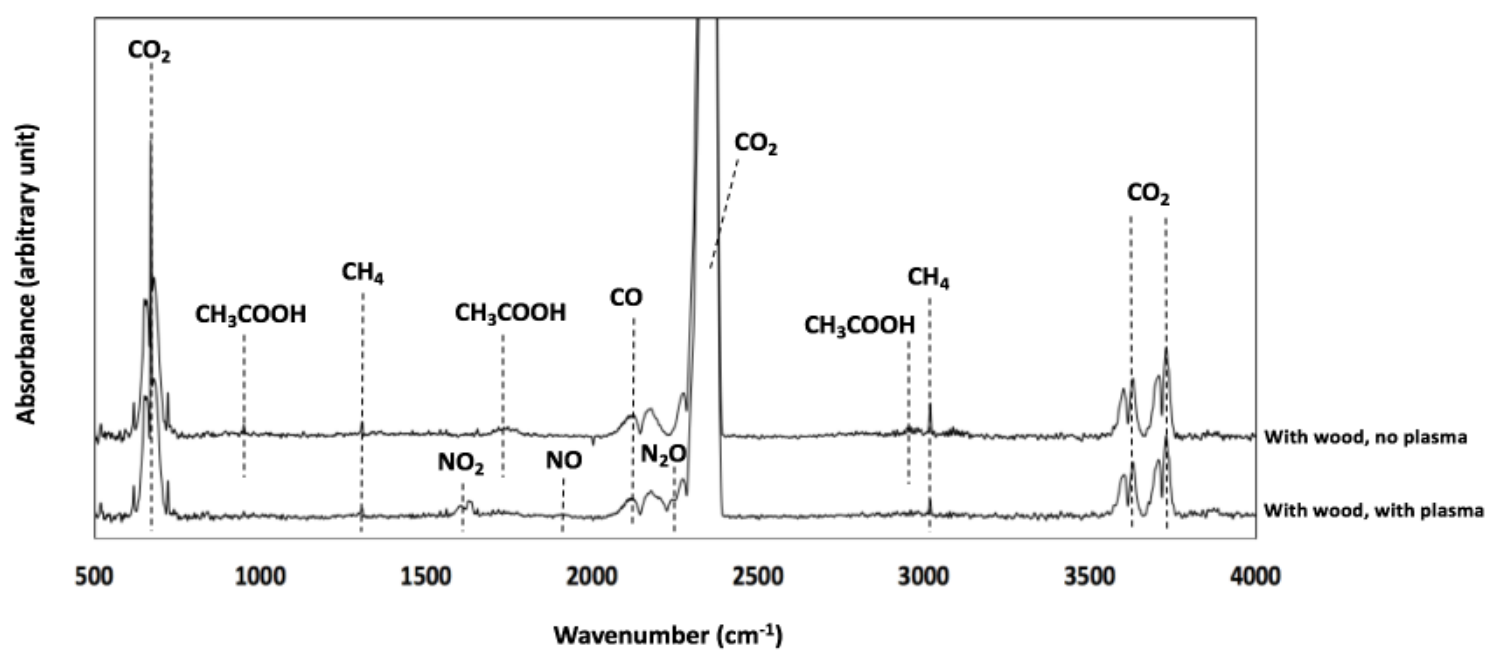


Figure 5 FTIR spectra of gaseous products with/without plasma running with wood fed into the fluidised bed (in $\mathrm{N}_{2}$ ) of alumina sand at $873 \mathrm{~K}$.

\subsubsection{Effect of plasma power and carbon balance}

\section{- Effect of plasma power}

The effect of the supplied power on the destruction of the carbon-containing compounds inside the plasma reactor was also investigated. This was carried out with a bed of mayenite-supported $\mathrm{CuO}$ fluidised by pure $\mathrm{N}_{2}$ at $873 \mathrm{~K}$. The reason for testing the system in the bed of mayenite-supported $\mathrm{CuO}$ was that it is more reactive than $\mathrm{Fe}_{2} \mathrm{O}_{3}$ for combustion and thus expected to generate the lowest amount of tar, and hence would require the most sensitive measurements. Figure 6 gives mole fraction of primary carbon-containing species leaving the plasma reactor after a batch of wood had been added to the fluidised bed, as a function of increasing plasma input power (from 0 to $17.1 \mathrm{~W}$, corresponding to SED values from 0 to $1027 \mathrm{~J} / \mathrm{L}$ ). The time taken for complete pyrolysis in each experiment was reproducible ( $\sim 30 \mathrm{~s})$, as shown in Fig. 6 . It can be seen that as the SED was increased, the mole fraction of $\mathrm{CO}$ increased accordingly, while $\mathrm{CO}_{2}$ was not affected significantly. The apparent rate of production of $\mathrm{CH}_{4}$ decreased with the increase in the plasma power. This suggests that when the tar was transported into the hot plasma reactor, most of the tar was converted into $\mathrm{CO}$ and some of the $\mathrm{CH}_{4}$ produced from pyrolysis was burned. The observations here were similar to those of Huu et al. [24] and Baylet et al. [31]. They both investigated $\mathrm{CH}_{4}$ conversion using DBD. Under operating conditions similar to the current study $\left(>200^{\circ} \mathrm{C}\right.$, and a gas mixture of $\mathrm{N}_{2} / \mathrm{O}_{2} / \mathrm{CO}_{2}$ in the plasma reactor, and similar DBD geometry), they found $\mathrm{CH}_{4}$ in plasma was converted primarily into $\mathrm{CO}$, with a small proportion converting to $\mathrm{CO}_{2}$. 

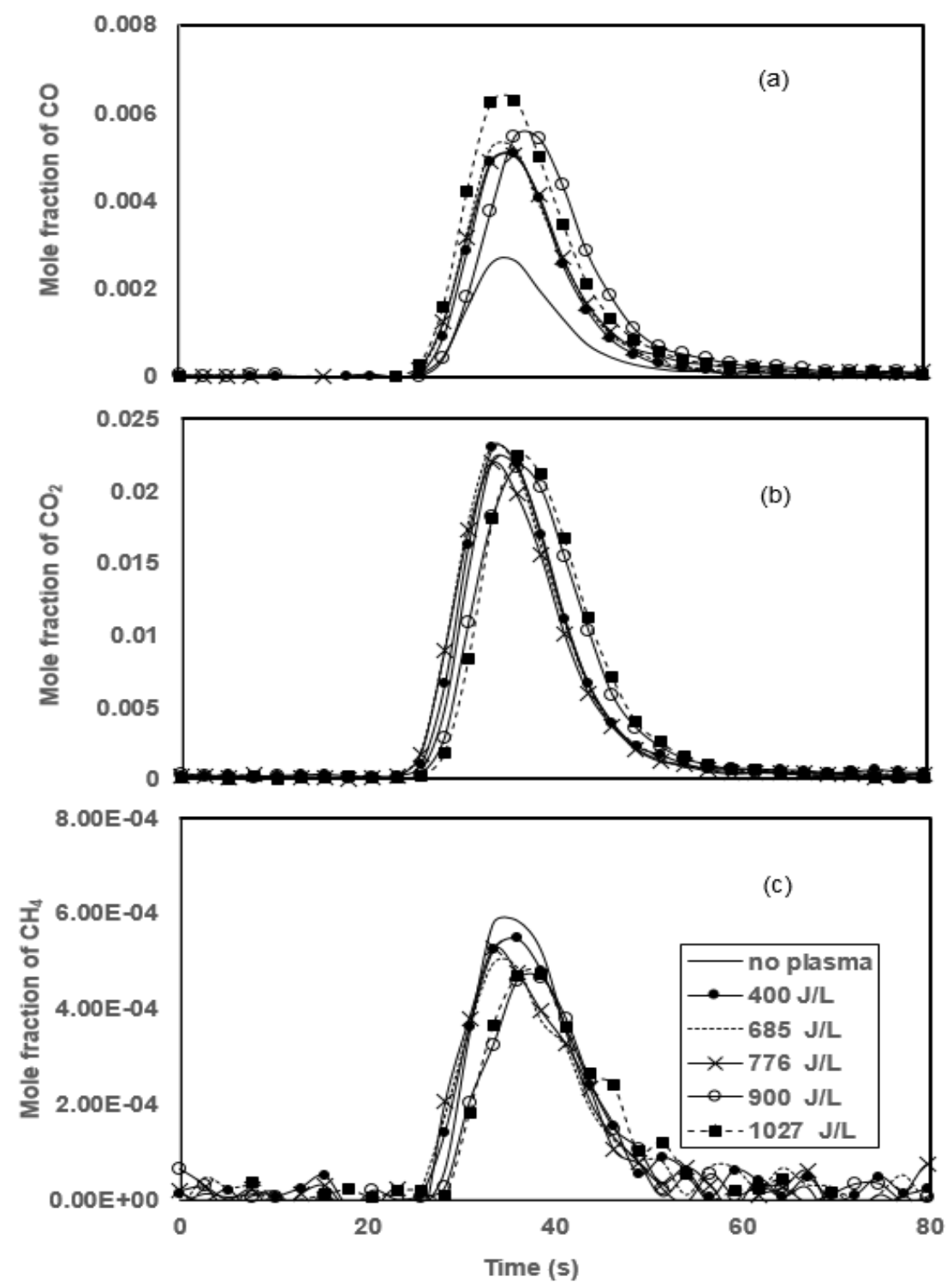

Figure 6 Mole fraction of carbon-containing gaseous species detected (with dilution by air) at $873 \mathrm{~K}$ in a fluidised bed of mayenite-supported $\mathrm{CuO}$ of for different SED values of the plasma reactor, (a) $\mathrm{CO}$, (b) $\mathrm{CO}_{2}$, (c) $\mathrm{CH}_{4}$. 


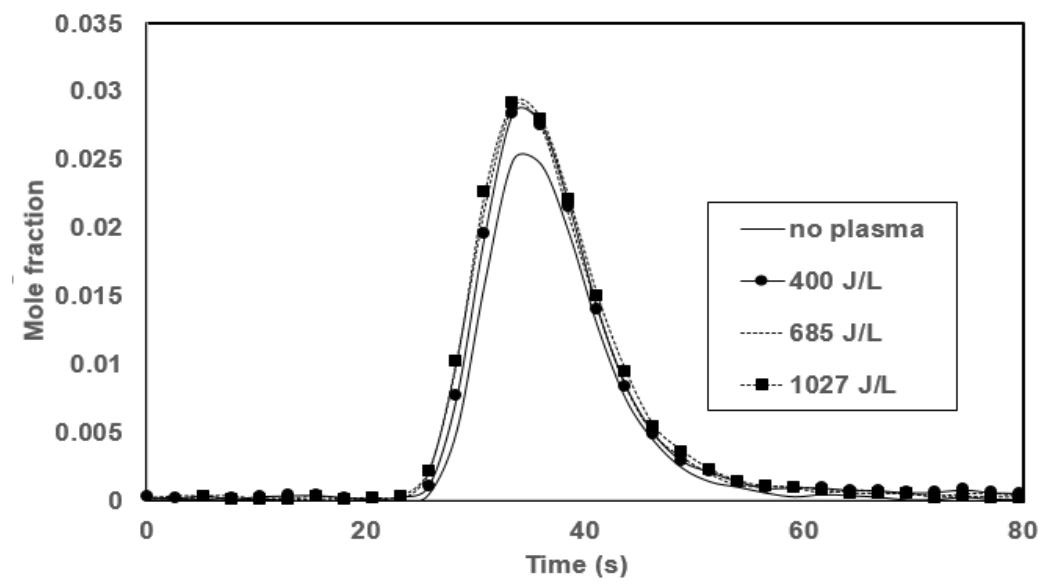

Figure 7 Overall mole fraction profiles of carbon-containing gaseous species $\left(\mathrm{CO}+\mathrm{CO}_{2}+\mathrm{CH}_{4}\right)$ detected (with dilution by air) at $873 \mathrm{~K}$ in a fluidised bed of mayenite-supported $\mathrm{CuO}$, under different SED values of the plasma reactor.

Figure 7 shows the overall mole fraction of all carbon-containing species detected by FTIR. The measurement system has $\sim 18$ seconds response time (time taken for the FTIR signal change from 5\% to $95 \%$ of full response to a step change). Any difference between the curves would suggest a difference in the amount of carbon in tar being burned in the plasma. The difference between the curves with no plasma and plasma with a SED of $1027 \mathrm{~J} / \mathrm{L}$, gives the rate of conversion of the carbon in tar to detectable carbon-containing species, and hence the tar content of the gas entering the sample line. This difference in the total mole fraction of carbon in $\mathrm{CH}_{4}+\mathrm{CO}+\mathrm{CO}_{2}$ is shown in Figure 8 for wood pyrolysing at 873 $\mathrm{K}$ in mayenite-supported $\mathrm{CuO}$. Figure 8 would allow the rate of tar production to be measured as a function of time; however, in this case (with an experiment lasting only $\sim 30 \mathrm{~s}$, and a mixing time of 18 s), the result is strongly influenced by mixing in the sample line and would require deconvolution. Future studies looking at rates of pyrolysis would require further opimisation of the time response (which here is dominated by the FTIR) of the sample system. Here, however, total quantities, the main interest, are unaffected by the sampling system response time. 


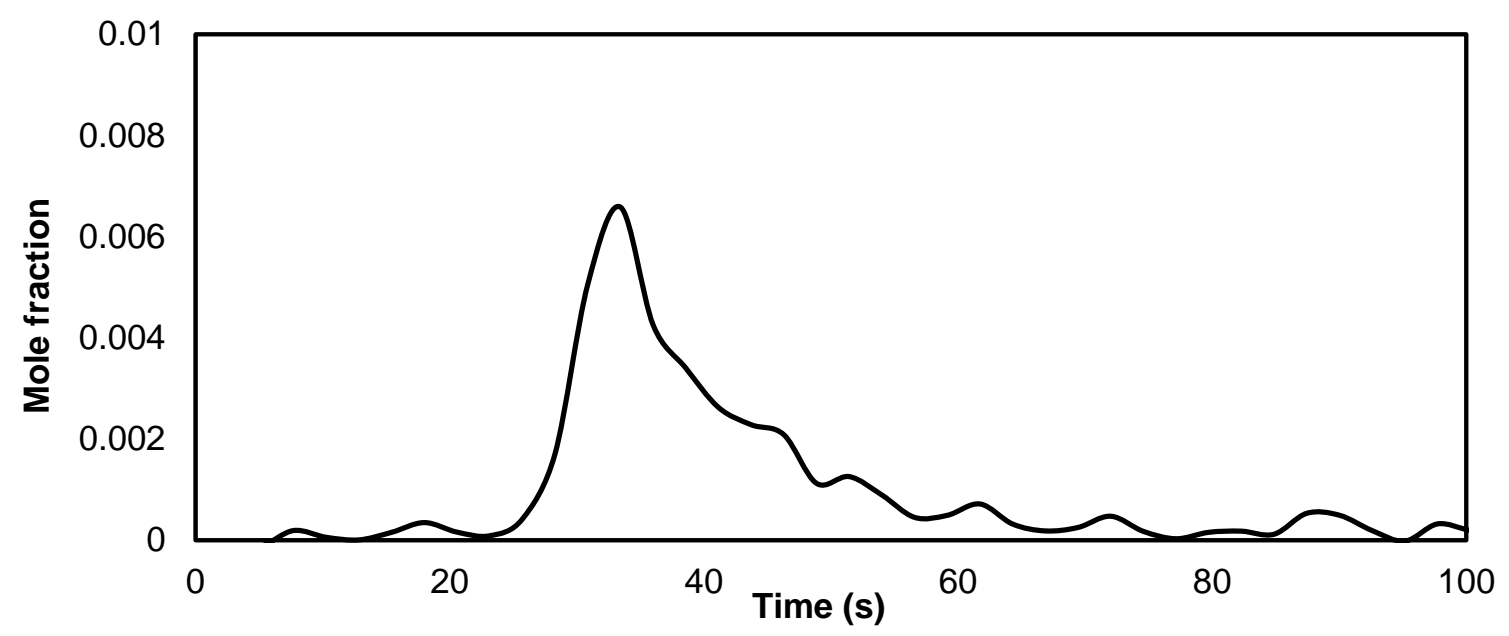

Figure 8 Additional total molar fraction of carbon in detectable species $\left(\mathrm{CO}, \mathrm{CH}_{4}\right.$ and $\left.\mathrm{CO}_{2}\right)$ upon activation of plasma. The sample was pyrolyised in a bed of mayenite-supported $\mathrm{CuO}$. at $873 \mathrm{~K}$.

\section{- Carbon balance}

No visible deposits of tar or carbon fines were observed in the trapping tube. As shown in Table 3, good carbon balances $(0.89-0.94)$ were obtained when plasma was present. The overall carbon balance increased a little with an increase in plasma SED from 400 to $1027 \mathrm{~J} / \mathrm{L}$, but not by a significant amount. Increasing the power seems only to result in more significant conversion of $\mathrm{CH}_{4}$ to $\mathrm{CO}$. Most of the produced tar in the fluidised bed had been combusted (or converted to methane) in the presence of plasma at low power, thus further increase in power did not result in an increase in the overall rate of conversion to $\left(\mathrm{CH}_{4}+\mathrm{CO}+\mathrm{CO}_{2}\right)$.

Table 3 Total carbon balance as $\mathrm{CO}, \mathrm{CO}_{2}$ and $\mathrm{CH}_{4}$ under different plasma SED (base on pure carbon as the tar compound), with the fluidised bed in mayenite-supported $\mathrm{CuO}$ and at $873 \mathrm{~K}$.

\begin{tabular}{|c|c|}
\hline SED (J/L) & Total carbon balance (air-dried) \\
\hline 0 (no plasma) & $0.73 \pm 0.02$ \\
\hline 400 & $0.89 \pm 0.02$ \\
\hline 685 & $0.90 \pm 0.03$ \\
\hline 776 & $0.92 \pm 0.02$ \\
\hline 900 & $0.93 \pm 0.02$ \\
\hline 1027 & $0.94 \pm 0.02$ \\
\hline
\end{tabular}


Though relatively high carbon balances were observed in Table 3, they were not as high as close to unity, and the operating temperature of the fluidised bed might have an effect on this. The investigations of the effects of temperature and bed materials in the following sections were all carried out with plasma SED of $1027 \mathrm{~J} / \mathrm{L}$. Table 4 summarized the results of carbon balance under each experimental condition, with change in the fluidising bed material and operating temperature. It was found that an increase in the temperature of the fluidised bed led to an improved carbon balance. The improved carbon balance with increased temperature suggests that either i) tar produced at higher temperatures was easier to convert in the plasma reactor, or ii) the hotter fluidised bed results in higher temperatures in the stream of gas and volatile matter entering the sampling line, and thus less likely to condense. The possibility of i) seems less likely to dominate here. Tars can be broadly classified into primary, secondary and tertiary tars, depending on their formation conditions [32]. The secondary and tertiary tar come from the primary tar, and the primary tar products are destroyed before tertiary tar appeared. Primary tar products usually appear in the temperature range between 500 to $800^{\circ} \mathrm{C}$, and tertiary tar starts to be generated from at $750^{\circ} \mathrm{C}$ and above [33]. Tertiary tar products are believed the most stable and difficult to crack catalytically [34]. Therefore, it is reasonable to predict that tars produced from higher temperatures in the fluidised bed should be harder to convert in the plasma reactor, unless there is some different activation route of plasma cracking.

Overall, the fact that the carbon balance is close to unity indicates that the majority of the carbon in the tars was fully converted to detectable species in the oxygen containing plasma.

Table 4 Total carbon balance with the fluidised bed loaded with different bed materials and at temperatures from 773 to $1173 \mathrm{~K}$ (based on pure carbon as the tar compound).

\begin{tabular}{|c|c|c|}
\hline Bed material & Bed temperature (K) & Carbon balance \\
\hline \multirow{2}{*}{$\begin{array}{c}\mathrm{N}_{2} \text { fluidised bed with } \\
\text { alumina sand }\end{array}$} & 773 & $0.86 \pm 0.02$ \\
\cline { 2 - 3 } & 873 & $0.85 \pm 0.04$ \\
\cline { 2 - 3 } & 973 & $0.96 \pm 0.02$ \\
\hline
\end{tabular}




\begin{tabular}{|c|c|c|}
\hline & 1073 & $1.02 \pm 0.05$ \\
\hline & 1173 & $1.04 \pm 0.03$ \\
\hline \multirow{5}{*}{$\begin{array}{l}\mathrm{N}_{2} \text { fluidised bed with } \\
\qquad \mathrm{Fe}_{2} \mathrm{O}_{3}\end{array}$} & 773 & $0.85 \pm 0.03$ \\
\hline & 873 & $0.88 \pm 0.03$ \\
\hline & 973 & $0.98 \pm 0.02$ \\
\hline & 1073 & $0.94 \pm 0.03$ \\
\hline & 1173 & $1.00 \pm 0.03$ \\
\hline \multirow{5}{*}{$\begin{array}{c}\mathrm{N}_{2} \text { fluidised bed with } \\
\text { Mayenite-supported } \\
\mathrm{CuO}\end{array}$} & 773 & $0.91 \pm 0.03$ \\
\hline & 873 & $0.94 \pm 0.02$ \\
\hline & 973 & $0.96 \pm 0.02$ \\
\hline & 1073 & $0.98 \pm 0.03$ \\
\hline & 1173 & $0.97 \pm 0.03$ \\
\hline \multirow{5}{*}{$\begin{array}{c}\mathrm{N}_{2} \text { fluidised bed with } \\
\text { Mayenite-supported } \\
\mathrm{Cu}_{2} \mathrm{O}\end{array}$} & 773 & $0.92 \pm 0.03$ \\
\hline & 873 & $0.96 \pm 0.03$ \\
\hline & 973 & $0.98 \pm 0.03$ \\
\hline & 1073 & $1.00 \pm 0.02$ \\
\hline & 1173 & $0.99 \pm 0.03$ \\
\hline
\end{tabular}

\subsection{Pyrolysis of wood in alumina sand}

Figure 9 gives the yield of each carbon-containing species including $\mathrm{CO}, \mathrm{CO}_{2}, \mathrm{CH}_{4}$, tar and char from wood pyrolysis in alumina sand. The error bars show the range of results for three repetitions. Alumina sand is considered inert, thus chemical interaction with the wood particle is expected to be minimal. According to Fig. 9, an increase in temperature promoted the production of gases. The yield of $\mathrm{CH}_{4}$ increased from less than $0.1 \%$ to $1.9 \%$ on a weight basis from 773 to $1073 \mathrm{~K}$, with a maximum value of $2.5 \%$ at $973 \mathrm{~K}$. Then, a sharp increase in $\mathrm{CH}_{4}$ yield from 1073 to $1173 \mathrm{~K}$ was observed; meanwhile, there was a decrease in the yield of tar (in contrast to the gradual increase of tar yield from 773 to 1073 $\mathrm{K})$. This suggests that the $\mathrm{CH}_{4}$ could have come from the cracking of tar when the bed temperature is above $1073 \mathrm{~K}$. Below $1073 \mathrm{~K}$, the tar could have been mainly primary tar, which is consistent with the results by Evans and Milne (1997) [33]. When the temperature increased to $1173 \mathrm{~K}$, there could have 
been a conversion of primary tar to secondary or tertiary tar, resulting the generation of $\mathrm{CH}_{4}$. The yield of char was determined from the $\mathrm{CO}$ and $\mathrm{CO}_{2}$ produced during the burn-off period after pyrolysis. The char content gradually decreased from $\sim 29 \%$ to $\sim 17 \%$ due to more significant decomposition as the temperature increased from 773 to $1173 \mathrm{~K}$.

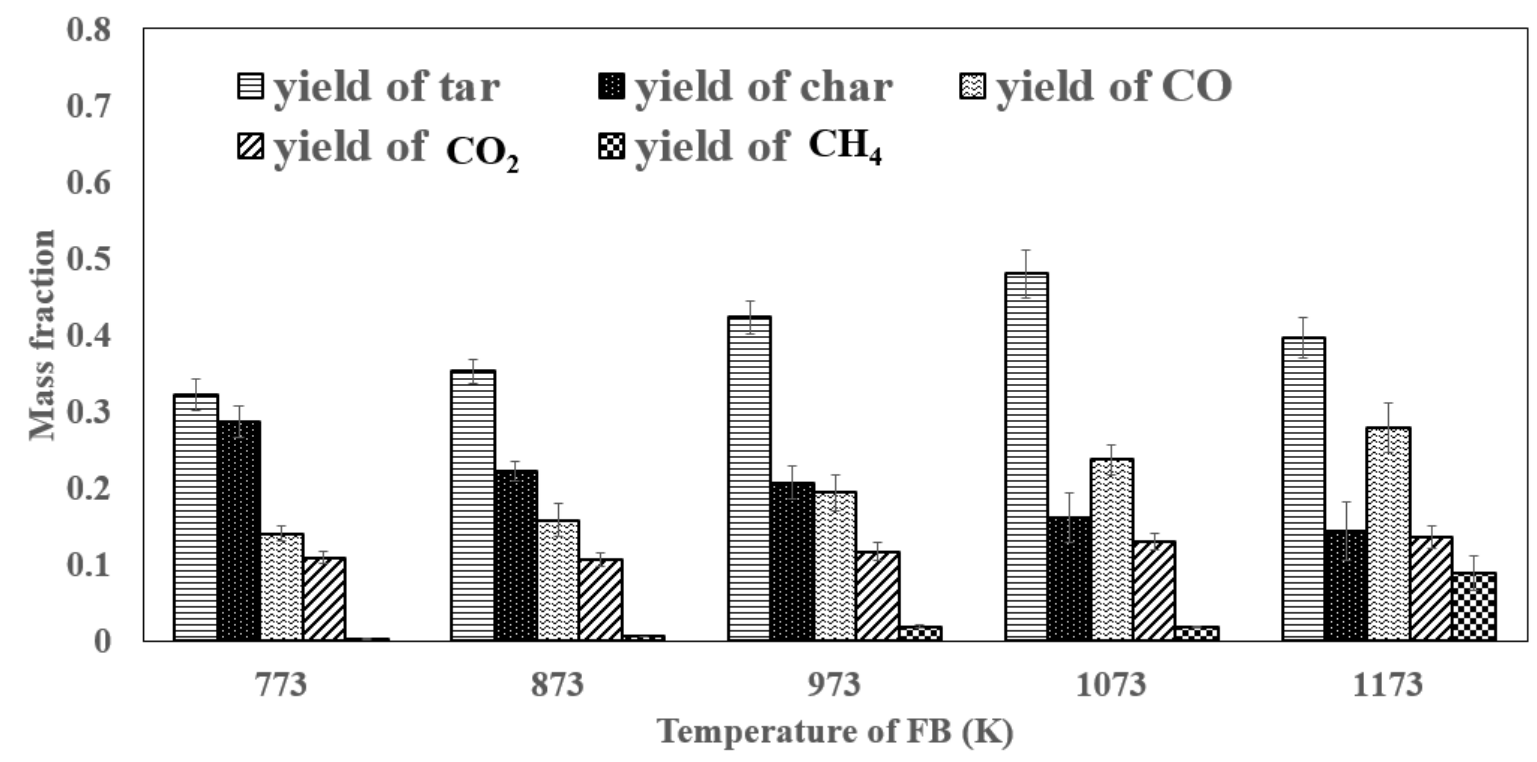

Figure 9 Yield (mass of carbon / mass of carbon in the fuel) of different carbon-containing product species in a bed of alumina sand from 773 to $1173 \mathrm{~K}$.

\subsection{Pyrolysis of wood with $\mathrm{Fe}_{2} \mathrm{O}_{3}$}

Figure 10 gives the yield of each product in a fluidised bed of $\mathrm{Fe}_{2} \mathrm{O}_{3}$. According to Fig. 10, at $773 \mathrm{~K}$, tars were the most significant product, $\sim 34 \%$ (of carbon). As the temperature increased, the amounts of $\mathrm{CO}_{2}$ significantly increased and became dominant at high temperatures. Comparing the results with those in the bed of alumina sand (Fig. 9), the yield of CO was similar in the two different bed materials from 773 to $973 \mathrm{~K}$; beyond $973 \mathrm{~K}$, the amount of $\mathrm{CO}$ produced in the $\mathrm{Fe}_{2} \mathrm{O}_{3}$ bed fell, probably because the $\mathrm{Fe}_{2} \mathrm{O}_{3}$ started to convert $\mathrm{CO}$ from $973 \mathrm{~K}$. The yield of tar was also found to be lower in $\mathrm{Fe}_{2} \mathrm{O}_{3}$ from 873 to $1173 \mathrm{~K}$, whilst the yield of $\mathrm{CO}_{2}$ was much higher, indicating combustion of pyrolysed tar by $\mathrm{Fe}_{2} \mathrm{O}_{3}$ to mostly $\mathrm{CO}_{2}$, when the temperature exceeded $873 \mathrm{~K}$. From 773 to $1073 \mathrm{~K}$, the yield of $\mathrm{CH}_{4}$ in $\mathrm{Fe}_{2} \mathrm{O}_{3}$ was higher than that in alumina sand; at $1173 \mathrm{~K}$, the value was lower. It seems that $\mathrm{CH}_{4}$ is also a 
product from the reaction between $\operatorname{tar}$ and $\mathrm{Fe}_{2} \mathrm{O}_{3}$ at low temperatures. When the temperature increased to $1173 \mathrm{~K}, \mathrm{Fe}_{2} \mathrm{O}_{3}$ became reactive for the conversion of $\mathrm{CH}_{4}$. Conversion of $\mathrm{CH}_{4}$ by $\mathrm{Fe}_{2} \mathrm{O}_{3}$-based materials usually occurs at temperatures above $1123 \mathrm{~K}$, depending on the composition, preparation method and particle size of the material $[35,36]$. The char yields in the beds of alumina sand and $\mathrm{Fe}_{2} \mathrm{O}_{3}$ were similar, indicating no direct solid-solid reaction between char and $\mathrm{Fe}_{2} \mathrm{O}_{3}$.

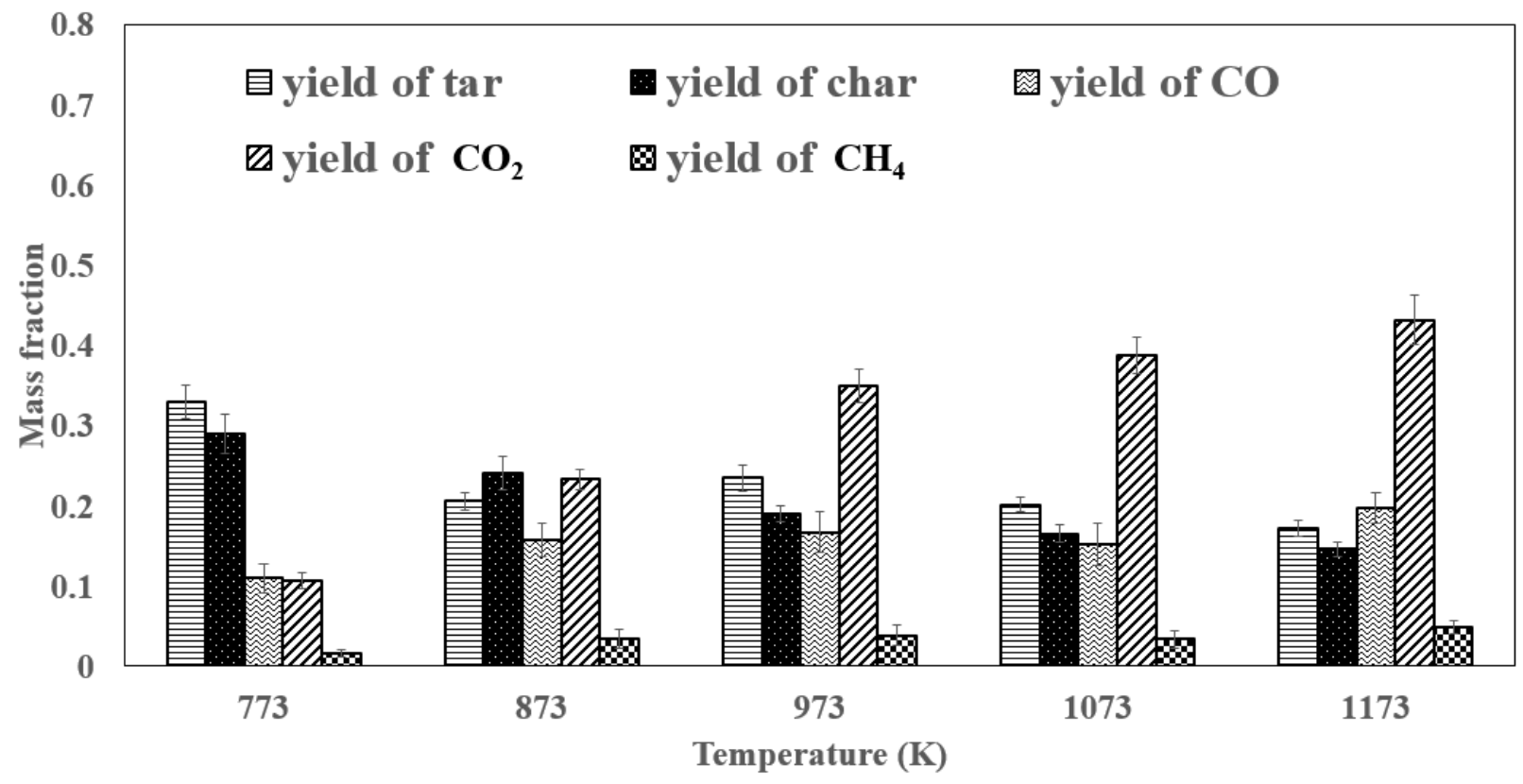

Figure 10 Yield (mass of carbon / mass of carbon in the fuel) of different carbon-containing species in a bed of $\mathrm{Fe}_{2} \mathrm{O}_{3}$ from 773 to $1173 \mathrm{~K}$.

\subsection{Pyrolysis of wood with mayenite-supported $\mathrm{CuO}$ and $\mathrm{Cu}_{2} \mathrm{O}$}

Figure 11 shows the yield of each product in a fluidised bed of $\mathrm{CuO}$ supported on mayenite. Comparing Figs. 11 and 9, mayenite-supported $\mathrm{CuO}$ was effective in combusting pyrolysis products in situ. The products of pyrolysis were converted mainly to $\mathrm{CO}_{2}$, especially at $1173 \mathrm{~K}$, where $\mathrm{CO}_{2}$ constituted of $87 \%$ of the products. Comparing the results with the pyrolysis in $\mathrm{Fe}_{2} \mathrm{O}_{3}$, mayenite-supported $\mathrm{CuO}$ exhibited higher reactivity for the conversion of pyrolysis products to $\mathrm{CO}_{2}$. Similar to $\mathrm{Fe}_{2} \mathrm{O}_{3}$ and alumina sand, there was no significant solid-solid reaction between mayenite-supported $\mathrm{CuO}$ and char from 773 to $1073 \mathrm{~K}$. When the temperature reached $1173 \mathrm{~K}$, mayenite-supported $\mathrm{CuO}$ consumed most 
of the char generated. This high reactivity of mayenite-supported $\mathrm{CuO}$ at $1173 \mathrm{~K}$ could have come from the change in the form of oxygen supply. $\mathrm{CuO}$ tends to release significant amount of gaseous oxygen [37] and form $\mathrm{Cu}_{2} \mathrm{O}: \mathrm{CuO}=\mathrm{Cu}_{2} \mathrm{O}+\mathrm{O}_{2}$. At low temperatures, this effect can be ignored. At $1173 \mathrm{~K}$, due to the presence of gaseous oxygen, there seem to have been both gas-gas reaction between gaseous pyrolysis products and released oxygen, and solid-gas reaction between char and the released oxygen. The effect of released oxygen from $\mathrm{CuO}$ at higher temperatures was further confirmed by comparing the results from a bed of $\mathrm{Cu}_{2} \mathrm{O}$ (which does not release oxygen).

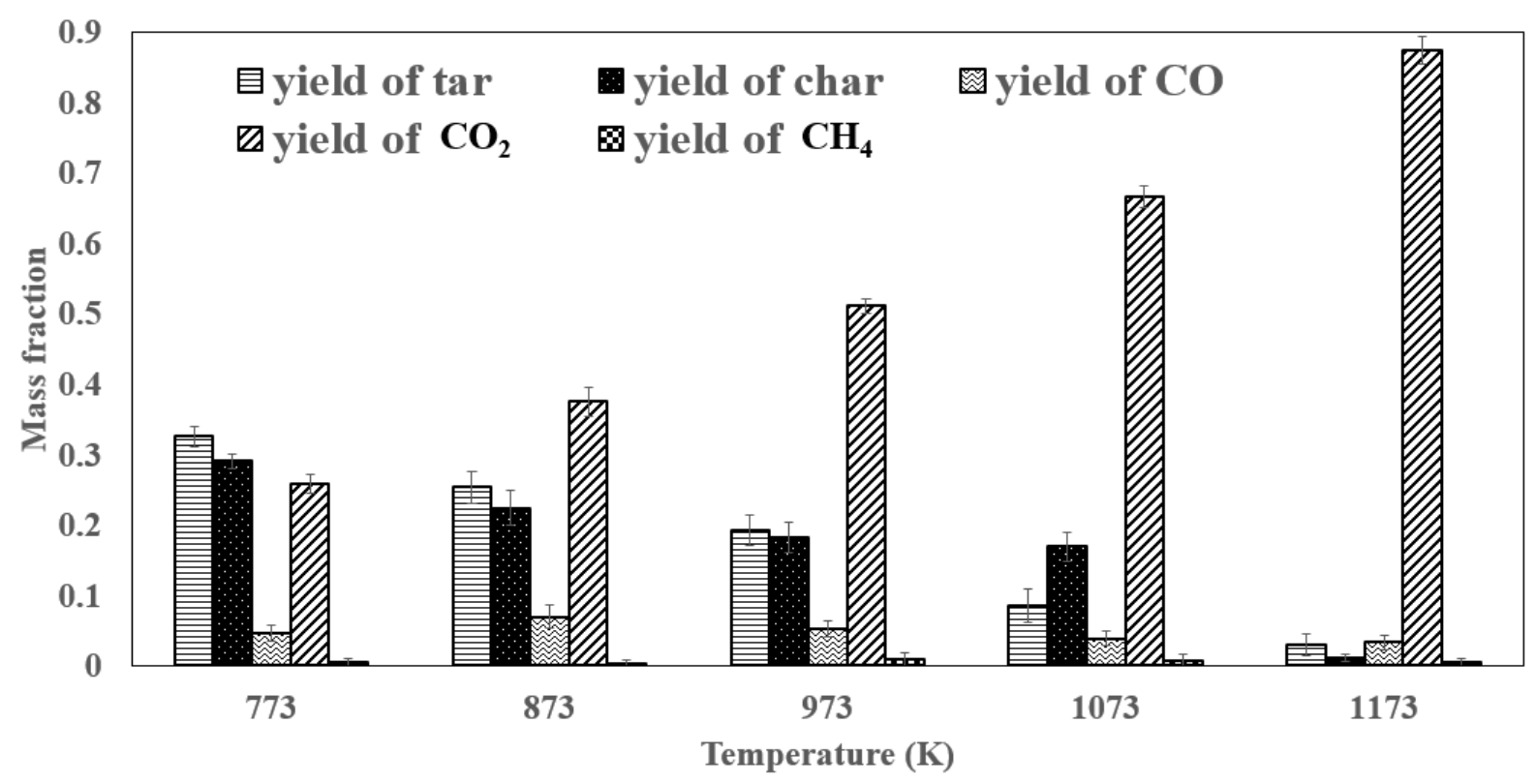

Figure 11 Yield (mass of carbon / mass of carbon in the fuel) of different carbon-containing products species in a bed of mayenite-supported $\mathrm{CuO}$ from 773 to $1173 \mathrm{~K}$.

Figure 12 shows the pyrolysis of wood chips in a bed of mayenite-supported $\mathrm{Cu}_{2} \mathrm{O}$. For each temperature, with and without plasma, experiments were carried out consecutively, with no regeneration between the two (to prevent re-oxidation to the $\mathrm{CuO}$ ). The amount of oxygen available in the $\mathrm{Cu}_{2} \mathrm{O}$ was always in excess of that needed for complete combustion (i.e. $\sim 0.88 \mathrm{~g}^{\circ} \mathrm{Cu}_{2} \mathrm{O}$ was needed for every $0.0538 \mathrm{~g}$ wood) for two experiments. To remove any systematic effect of the order in which the experiments were performed, experiments were repeated with the order of the two reversed; this showed the results were not influenced by the conversion of the oxygen carrier. After two 
experiments at each temperature, the bed was burned off in air to quantify the amount of char. The amount of char at each temperature was then obtained by taking half of carbon content in $\mathrm{CO}$ and $\mathrm{CO}_{2}$ generated during burn-off.

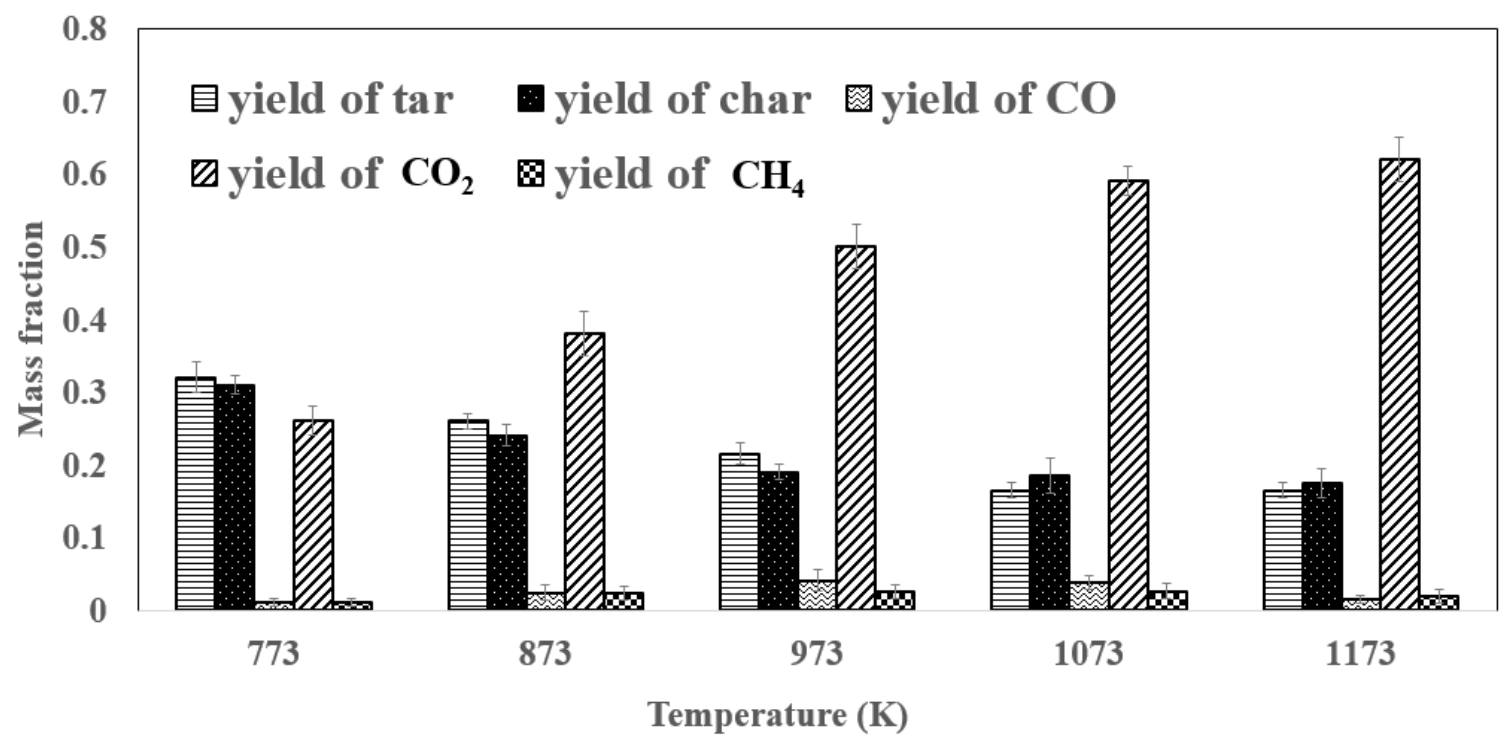

Figure 12 Yield (mass of carbon / mass of carbon in the fuel) of different carbon-containing products species in a bed of mayenite-supported $\mathrm{Cu}_{2} \mathrm{O}$ from 773 to $1173 \mathrm{~K}$.

\section{Discussion}

\subsection{Approach to tar quantification}

The use of an oxygen containing DBD plasma to convert volatile (i.e. tarry) species was shown to give good results in the experiments outline here. The key uncertainty was whether the plasma was able to convert all the species entering the sampling line into species detectable by the gas analyser. The good carbon balances obtained here, showed that for these experiments, all the carbon could be accounted for correctly, indicating complete or near complete conversion of the tars. Ideally, the downstream analysis of the gases could use relatively cheap infra-red analysers, rather than the more costly FTIR used here. Here, the carbon in the tar was defined to be any material that condensed in the trap at $0^{\circ} \mathrm{C}$ that was not carbon in $\mathrm{CH}_{4}, \mathrm{CO}_{2}$ or $\mathrm{CO}$. Any lighter species entering the plasma reactor that did not condense would have produce erroneous values. In this particular case, using an FTIR confirmed that only trace amounts of such species were produced, and not in sufficient quantity to substantially alter the carbon balance. As noted, in the introduction, the definition of "tar" is somewhat arbitrary and must 
either be related to a standard or it is effectively defined by how it is collected. The choice of the $0^{\circ} \mathrm{C}$ is in line with other works [38,39], which also used trapping system in ice bath for tar collection from upstream. The trapping system used here could be modified to change the tars collected, if required. However, here the main interest was in being able to account for the fate of the carbon released by the volatile matter.

Another significant issue with the method for measuring tar used here is that it is time-consuming (i.e. requiring two experiments) and does not give an instantaneous online measurement. Other ways of carrying out the tar measurement were also attempted. Firstly, an idea of using two sampling lines was tested. The sampling line from the fluidised bed to the point where the air was introduced was unchanged. After the air mixing, the stream was divided into two, with $50 \%$ of the flow going to a "blank" reactor with the same dimensions as the plasma reactor prior to an analyser, the other going to the plasma reactor prior to FTIR. The difference between the signals from the two analysers indicates the amount of tar entering each sampling line. This method simplified the experimental procedure, as only one experiment was needed to measure the tar yield. However, it was found difficult to control the flow conditions in the two sampling lines to be perfectly identical. Any variation between the two flow rates led to significant differences in the results. Additionally, the error caused by the difference in calibration, and residence time of the two analysers (in addition to the FTIR, and an infrared photometer Uras26 ABB analyser was also used) could not be neglected. Practically, better engineering of the two sampling lines, more stringent control of the flow rates, and using identical analysers would largely increase the feasibility of the application of this method. Secondly, the plasma was pulsed on and off during one experiment. In a continuous pyrolysis process, where the tar fraction does not change with time, it is possible to apply this approach. However, the idea was found to be unsuitable for the experiments here because the response time of the plasma reactor (i.e. on/off) must be quick enough than the pyrolysis time. Here, the plasma system took $\sim 5$ seconds to fully activate or deactivate, which is not sufficiently short compared to $\sim 30$ seconds pyrolysis time here. Thus, although the method used here to quantify the tar worked well, more work is needed if this method is to be adapted for general use. 


\subsection{Reactivity of pyrolysis products with oxygen carriers}

The order of reactivity of pyrolysis products $\left(\mathrm{CO}, \mathrm{CH}_{4}\right.$, tar) with active bed materials can be determined by comparing Figs. 9, 10, and 11. According to Figs. 9 and 10, at the lowest temperature (773 K), the presence of $\mathrm{Fe}_{2} \mathrm{O}_{3}$ caused a slight decrease in $\mathrm{CO}$ and tar yields; the yield of $\mathrm{CH}_{4}$ increased a little due to the decomposition of tar. Thus, $\mathrm{CO}$ and tar are more reactive towards the oxygen carriers than $\mathrm{CH}_{4}$. This is consistent with the reported findings that the oxidation of $\mathrm{CH}_{4}$ by oxygen carriers $\left(e . g . \mathrm{Fe}_{2} \mathrm{O}_{3}\right)$ is usually more difficult than that of other carbon-containing species such as $\mathrm{CO}$ [40]. Comparing the product distribution at $773 \mathrm{~K}$ in alumina sand and mayenite-supported $\mathrm{CuO}$, there was a clear increase in $\mathrm{CO}_{2}$, and decrease in $\mathrm{CO}$ while no clear drop in tar yield in the bed of mayenite-supported $\mathrm{CuO}$. In this case, $\mathrm{CO}$ was considered to react more readily with the active bed materials. Thus, the order of the reactivity of gaseous product species is likely to be $\mathrm{CO}>\operatorname{tar}>\mathrm{CH}_{4}$.

$\mathrm{Fe}_{2} \mathrm{O}_{3}$, mayenite-supported $\mathrm{CuO}$ and mayenite-supported $\mathrm{Cu}_{2} \mathrm{O}$ all helped tar abatement inside the fluidised bed within the short residence time ( 1 second), as shown in Fig.13. The increase in temperature clearly improved the conversion of tar in the bed materials. Mayenite-supported $\mathrm{CuO}$ was especially effective for combustion at high temperatures (e.g. 1073 and $1173 \mathrm{~K}$ ), exhibiting its potential as an oxidant for the direct combustion of biomass in a fluidised bed system.

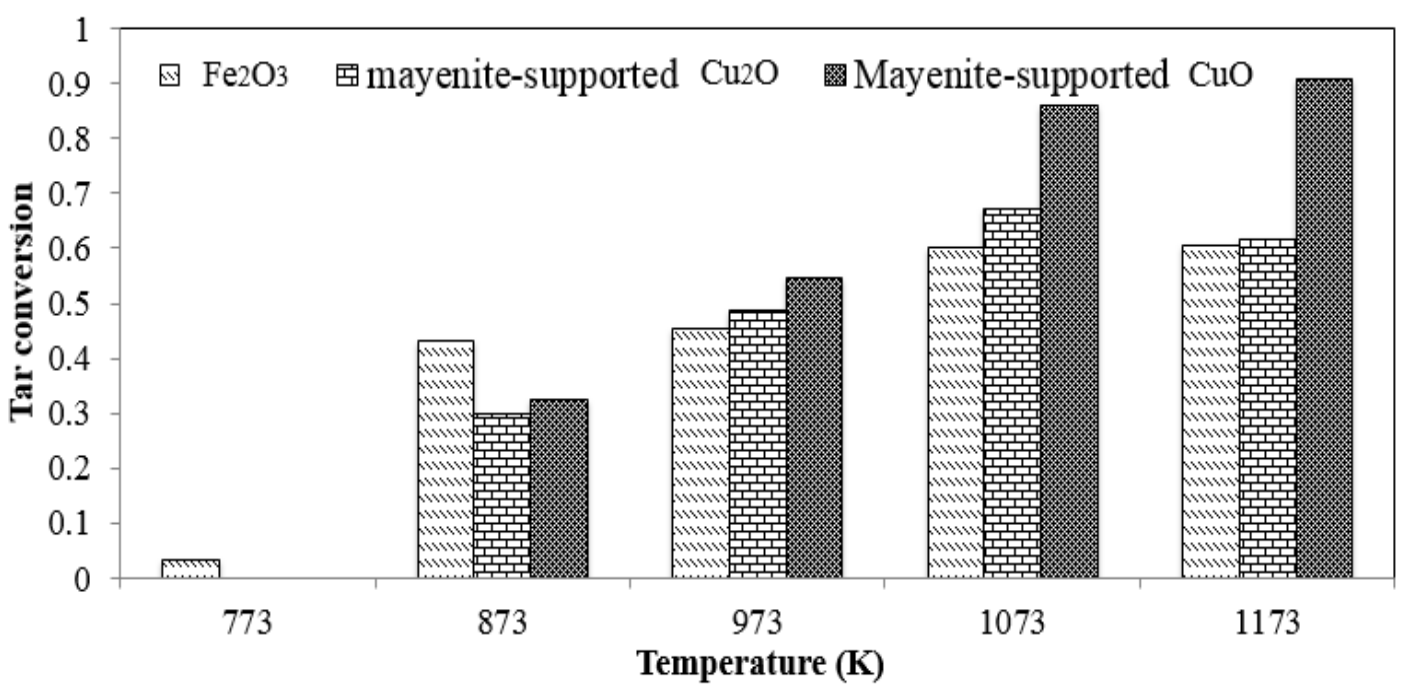

Figure 13 Tar conversions in different fluidised bed conditions. 
Mayenite has previously been shown to be an ideal support for $\mathrm{CuO}$ in chemical looping system if the CLOU effect is to be preserved [27]. Other support materials such as $\mathrm{Al}_{2} \mathrm{O}_{3}$ form mixed oxides with the copper oxide which can lead to agglomeration of the particles and reduce the partial pressure of oxygen [41]. At $1073 \mathrm{~K}$, the oxygen mole fraction at atmospheric pressure produced by $\mathrm{CuO}$ should be about 0.0016; at $1173 \mathrm{~K}$, it reached 0.018 (calculated from MTDATA [42]). Thus, at $1173 \mathrm{~K}$, there could have been both gas-gas reaction between gaseous pyrolysis products and released oxygen, and solidgas reaction between char and the oxygen.

Comparing the mole fractions of $\mathrm{CO}$, tar and $\mathrm{CH}_{4}$ in Figs. 11 and 12 , reactivity of $\mathrm{Cu}_{2} \mathrm{O}$ and $\mathrm{CuO}$ for the conversion tar was similar from 773 to $973 \mathrm{~K}$. More $\mathrm{CH}_{4}$ was detected in $\mathrm{Cu}_{2} \mathrm{O}$, indicating that $\mathrm{CuO}$ is more reactive than $\mathrm{Cu}_{2} \mathrm{O}$ towards $\mathrm{CH}_{4}$. When the temperature reached $1073 \mathrm{~K}$, the yield of $\operatorname{tar}$ in $\mathrm{CuO}$ dropped whilst it remained high in $\mathrm{Cu}_{2} \mathrm{O}$. At $1173 \mathrm{~K}$, the difference was more significant in that both tar and char still contributed a large portion to the total yield in a bed of $\mathrm{Cu}_{2} \mathrm{O}$, but not in $\mathrm{CuO}$. The clear difference observed at 1073 and $1173 \mathrm{~K}$ suggests that gaseous oxygen from $\mathrm{CuO}$ is the primary cause for the reduction of in the amounts of char and tar at $1173 \mathrm{~K}$.

\section{Conclusions}

(1) A plasma system for the on-line continuous quantification of tar was designed and placed in the downstream of a fluidised bed. The plasma system was found to be effective for tar conversion. The method for tar quantitation worked well, giving good carbon balances. Improvements to the response time of the gas analysers, and better control of the flow rates would allow more rapid measurements of the rates of tar production.

(2) Pyrolysis of wood with alumina sand in the fluidised bed was studied. It was shown that higher temperature promoted the production of gaseous products. Tar was found as the primary product from pyrolysis from 773 to $1173 \mathrm{~K}$. When the bed temperature increased to above $1073 \mathrm{~K}$, the tar formed cracked to $\mathrm{CH}_{4}$. 
(3) $\mathrm{Fe}_{2} \mathrm{O}_{3}$, mayenite-supported $\mathrm{Cu}_{2} \mathrm{O}$, and mayenite-supported $\mathrm{CuO}$ were found effective for in situ conversion of tar in the fluidised bed. The tar was mostly combusted to $\mathrm{CO}_{2}$. Mayenite-supported $\mathrm{CuO}$ was found to be the most reactive with the pyrolysis products, and was particularly effective for converting tar and char at $1173 \mathrm{~K}$ due to its ability to uncouple oxygen. The results demonstrated the promising feasibility of CLC or CLOU of biomass, without any active fluidising gas.

\section{Acknowledgement}

This work was supported by EP/L022427/1. Special thanks to the China Scholarship Council (CSC), and the Cambridge Trust for providing financial support for Yaoyao Zheng's PhD study at University of Cambridge. The authors would like to thank Dr. Ewa Marek for carrying out the XRD analysis, as well as providing advice and suggestions on this work.

\section{Supplementary materials}

\section{S1 $V-q$ Lissajous curve}

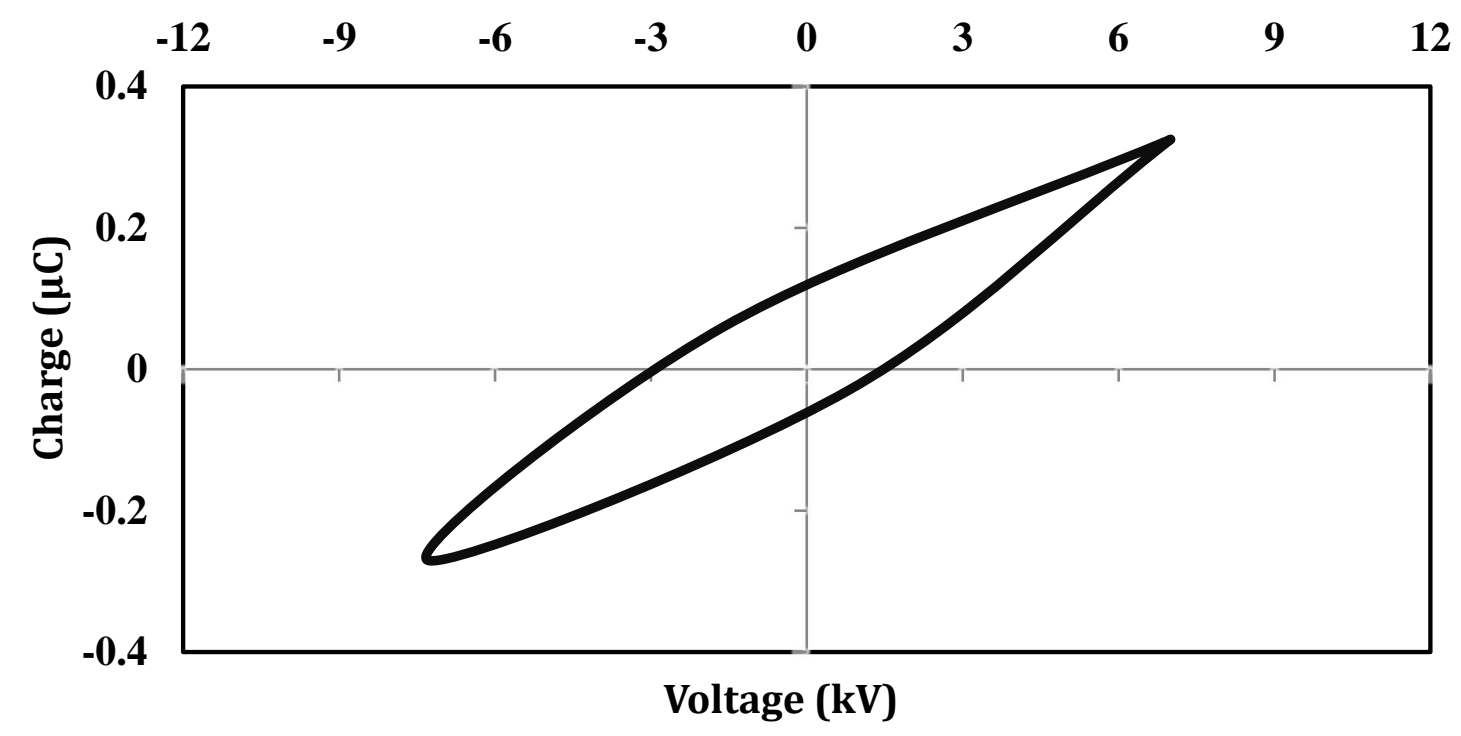

Figure S1 A typical $V-q$ Lissajous curve from a typical experiment, with frequency of $22 \mathrm{kHz}$, and voltage $14.4 \mathrm{kV}$ for the DBD reactor. The fluidised bed was operated at $873 \mathrm{~K}$, with mayenite-supported $\mathrm{CuO}$ as the bed. The sampled gas from the fluidised bed was diluted by air before entering the DBD reactor. The energy input was obtained by taking the area enclosed by the curve. 


\section{S2 Correction of the flow}

\section{Without plasma}

The change in composition of the gases can affect the total flow rate through the sampling line. In particular, the generated tar (without plasma running) appeared to block the sampling line. To resolve this issue for the purpose of tar quantification, a correction for the change in flow rate was applied. The air flow $F_{\text {air }}$ introduced to mix with product flow from the fluidised bed was assumed to be constant at $0.45 \mathrm{~L} / \mathrm{min}$, and when there was no plasma (i.e. oxygen was not consumed) the oxygen in the air flow was used as a tracer species. The total flow rate in the sampling line during the experiment $F_{\text {total }}$ could therefore be expressed as:

$$
F_{\text {total }}=\frac{F_{\text {air }} \times 0.21}{x_{\mathrm{O}_{2}}}
$$

Here, $x_{\mathrm{O}_{2}}$ is the mole fraction of oxygen detected by the ABB analyser, with 0.21 being oxygen mole fraction in undiluted air.

Ideally, if it is assumed that no change in sample gas flow occurs, the "ideal" mole fractions of product species detected by the analyser would be:

$$
\begin{array}{ll}
x_{i, \text { ideal }}=\frac{F_{\mathrm{FB}, \text { initial }} \times y_{i}}{F_{\mathrm{FB}, \text { initial }}+F_{\mathrm{air}}} & \text { Eq.S1 } \\
x_{i}=\frac{F_{\mathrm{FB}} \times y_{i}}{F_{\mathrm{FB}}+F_{\mathrm{air}}} . & \text { Eq.S2 }
\end{array}
$$

In Eq.S1, $x_{i, \text { ideal }}$ is the "ideal" mole fraction of the product species $i$ detected by the analyser, assuming negligible change in the total flow rate. $F_{\mathrm{FB} \text {,initial }}$ is initial flow rate of the gas stream that enters to the sampling line and $y_{i}$ is the mole fraction of species $i$ in the gas flow from the fluidised bed. For the nonideal case (when flow rate changes), the flow rate of the gas from the fluidised bed, $F_{\mathrm{FB}}$, will be lower than $F_{\mathrm{FB}, \text { initial}}$, which leads to lower measured mole fractions of the product species $i, x_{i}$. By combining Eqs.S1 and S2 to eliminate $y_{i}$, and rearranging: 


$$
x_{i, \text { corrected }}=\frac{x_{i} \times F_{\text {total }} \times F_{\mathrm{FB}, \text { initial }}}{F_{\text {total,initial }} \times F_{\mathrm{FB}}},
$$

where

$$
F_{\text {total }}=F_{\mathrm{FB}}+F_{\text {air }} \text {. }
$$

Corrected, "ideal" mole fractions of the products species were used for the calculation of yields.

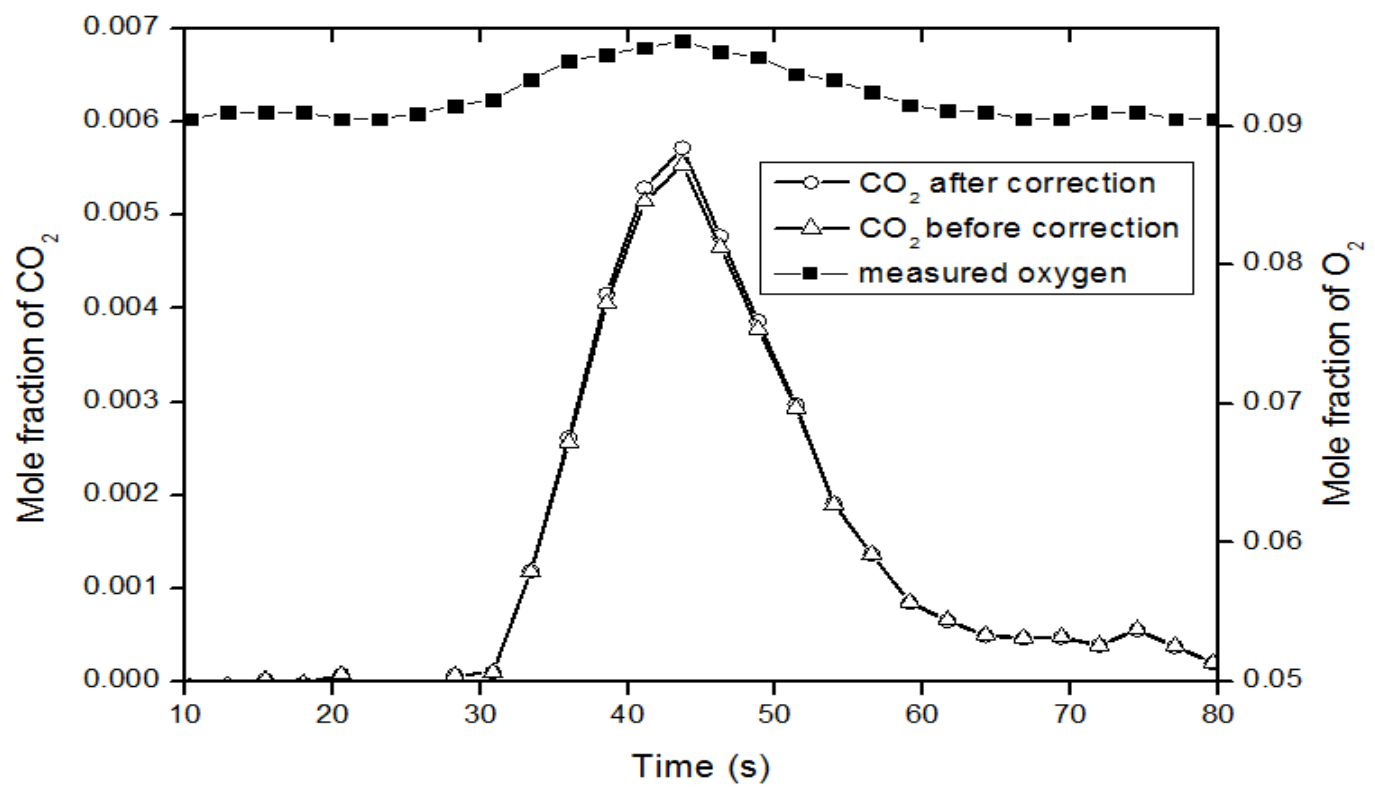

Figure S2 Mole fractions of $\mathrm{CO}_{2}$ before and after correction of the flow, with operating conditions of a $\mathrm{Fe}_{2} \mathrm{O}_{3}$ bed at $873 \mathrm{~K}$ in the fluidised bed without plasma discharge in the DBD reactor. The measured mole fraction of $\mathrm{O}_{2}$ is also shown. Note that the wood was fed into the fluidised bed at $t=30 \mathrm{~s}$.

Figure $\mathrm{S} 2$ shows the results in a $\mathrm{Fe}_{2} \mathrm{O}_{3}$ bed at $873 \mathrm{~K}$, without plasma running. The oxygen, which was expected to be inert, increased slightly when the wood was fed into the bed. The corrected $\mathrm{CO}_{2}$ curve based on the measured oxygen curve is largely similar to that before correction, suggesting that the change in the flow did not have a significant effect on the concentration of $\mathrm{CO}_{2}$ measured. A similar observation was made when using other gases and at different temperatures. 


\section{With plasma}

In the case when there was plasma, oxygen from the air stream can no longer be used as the trace species, as it was consumed to burn the tar and possibly convert $\mathrm{CO}$ to $\mathrm{CO}_{2}$. In order to correct for changes in the dilution, the oxygen concentration before the plasma reactor was required. It was assumed that the drop in the measured oxygen level was all used to burn the tar and possibly convert $\mathrm{CO}$ to $\mathrm{CO}_{2}$. Assuming that the tar was oxygen-free, then the difference in total $\mathrm{O}_{2}$ content in the $\mathrm{CO}$ and $\mathrm{CO}_{2}$ between the experiments with and without plasma all comes from the oxygen being consumed. Oxygen was also being consumed to produce water during tar combustion, and this amount depends on the chemical formula of the tar:

$$
\mathrm{C}_{x} \mathrm{H}_{y}+\left(x+\frac{1}{4} y\right) \mathrm{O}_{2}=x \mathrm{CO}_{2}+\frac{1}{2} y \mathrm{H}_{2} \mathrm{O}
$$

The amount of oxygen consumed for converting the carbon in tar to $\mathrm{CO}$ and $\mathrm{CO}_{2}, F_{\mathrm{O}_{2}, \mathrm{C}}$, is,

$$
F_{\mathrm{O}_{2}, \mathrm{C}}=\left(\frac{1}{2} F_{\mathrm{co}, \mathrm{on}}+F_{\mathrm{CO}_{2}, \mathrm{on}}\right)-\left(\frac{1}{2} F_{\mathrm{co}, \mathrm{off}}+F_{\mathrm{CO}_{2}, \mathrm{off}}\right) .
$$

Here, $F_{\mathrm{O}_{2}, \mathrm{C}}$ is the molar flow rate of oxygen consumed for burning the carbon content of tar, $F_{\mathrm{co}, \mathrm{on}}$ and $F_{\mathrm{CO}_{2} \text {,on }}$ are respectively the mole flow rate of $\mathrm{CO}$ and $\mathrm{CO}_{2}$ with plasma running, and subscript 'off' indicates the condition without plasma. Taking into account the stoichiometry of the tar, $F_{\mathrm{O}_{2}}$,tar , the mole flow rate of oxygen consumed for burning the tar is,

$$
F_{\mathrm{O}_{2}, \mathrm{tar}}=F_{\mathrm{O}_{2}, \mathrm{C}} *\left(1+\frac{\frac{1}{4} y}{x}\right)
$$

The flow of oxygen through the sampling line, in the absence of combustion, i.e. the flow entering the plasma reactor, is then

$$
F_{\mathrm{O}_{2}}=F_{\mathrm{O}_{2}, \text { tar }}+F_{\mathrm{O}_{2} \text {, measured }}
$$

Figure S3 shows the comparison of before and after correction to the flowrates of the mole fractions obtained from a bed of $\mathrm{Fe}_{2} \mathrm{O}_{3}$ at $873 \mathrm{~K}$. In Figure S3 (a), the measured oxygen level significantly fell when the wood was dropped into the fluidised bed. All the three tar compounds could restore the oxygen 
profile at the inlet of the plasma reactor, to close to the initial value, among which the correction based on pure carbon appeared to be the best. However, a tar compound should contain some hydrogen. The fact that pure carbon could restore the oxygen profile best is a combined effect of: 1) the tar itself might be mainly aromatics, which has very high $\mathrm{C}$ to $\mathrm{H}$ ratio; 2) the tar might contain some oxygen, which would lead to an over-estimation of the oxygen consumed for burning the carbon content in the tar; 3) incomplete combustion in the plasma reactor; 4) fluctuation in the background flow.

Figure $\mathrm{S} 3$ (b) gives the corrected $\mathrm{CO}_{2}$ mole fraction based on an oxygen level restored using pure carbon tar compound. There is tiny difference between the corrected and the measured values, suggesting that with plasma running there is no need to correct for changes in dilution in the sampling line; qualitatively, little change in flow was observed when the plasma was active.

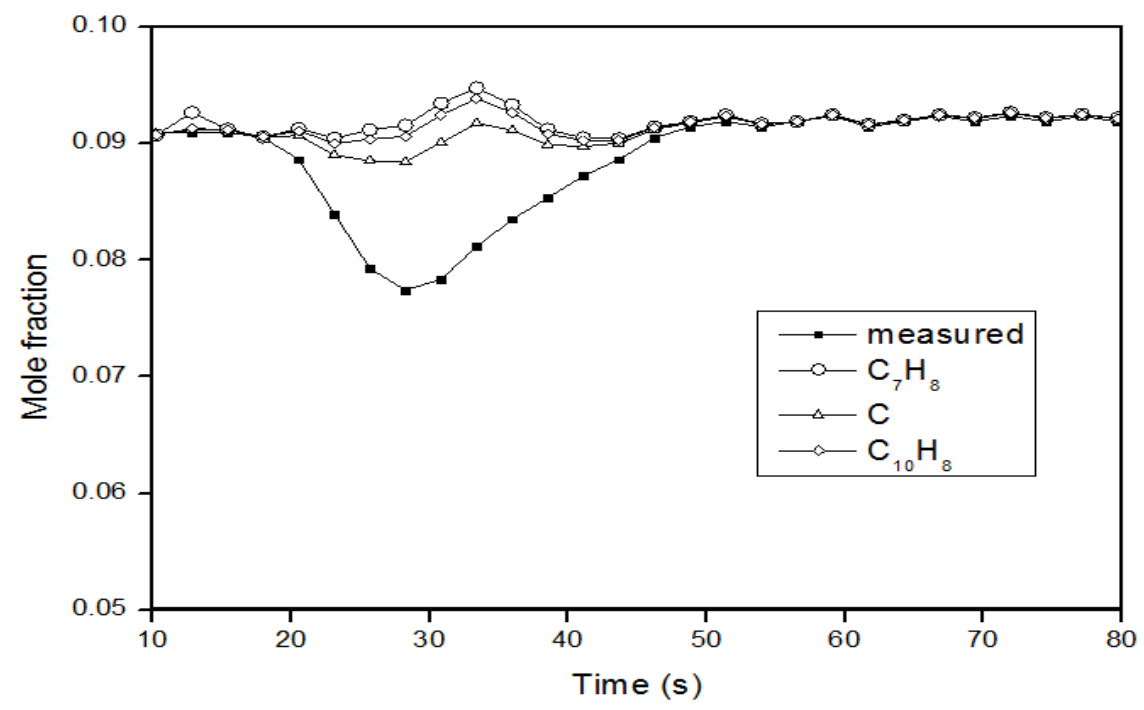

(a) 


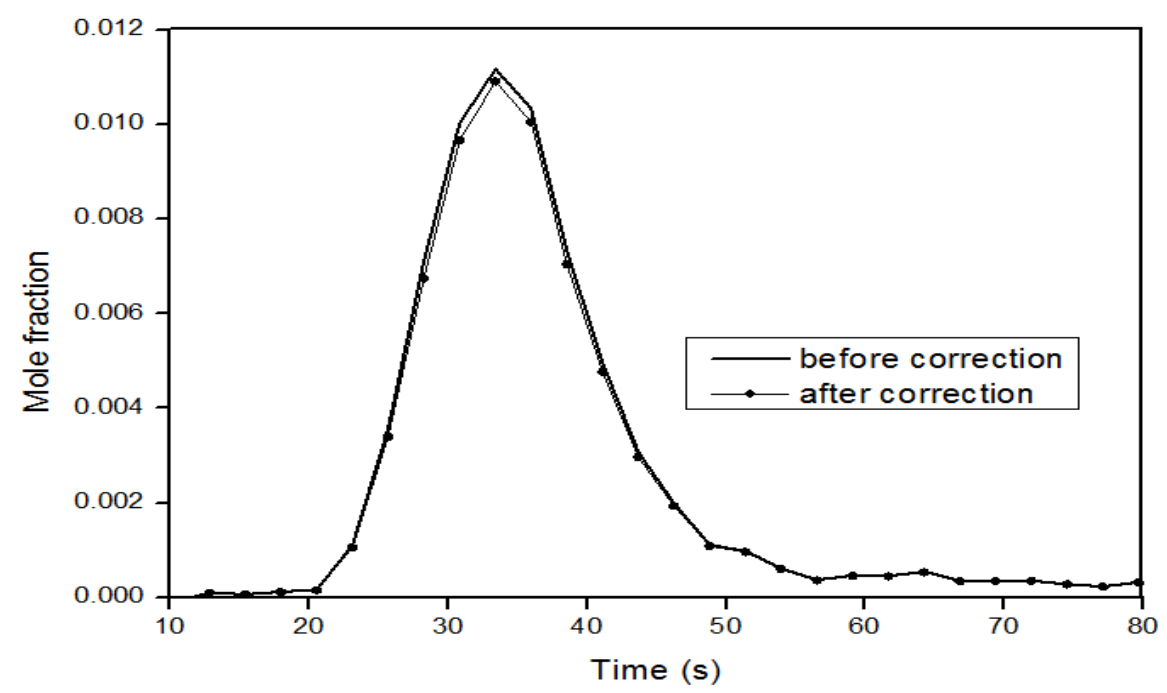

(b)

Figure S3 Mole fraction profiles at $873 \mathrm{~K}$ in a $\mathrm{Fe}_{2} \mathrm{O}_{3}$ bed with plasma discharge a) measured oxygen mole fraction and calculated mole fraction at the inlet to the plasma reactor, based on different tar compound b) comparison of the $\mathrm{CO}_{2}$ before and after correction of the flow. Note that the plasma was turned on at $t=10 \mathrm{~s}$, and wood was fed into the fluidised bed at $t=20 \mathrm{~s}$.

\section{Reference}

[1] J. Adanez, A. Abad, F. Garcia-Labiano, P. Gayan, L.F. de Diego, Progress in Chemical-Looping Combustion and Reforming technologies, Prog. Energy Combust. Sci. 38 (2012) 215-282. doi:10.1016/j.pecs.2011.09.001.

[2] L.-S. Fan, F. Li, Chemical Looping Technology and Its Fossil Energy Conversion Applications, Ind. Eng. Chem. Res. 49 (2010) 10200-10211. doi:10.1021/ie1005542.

[3] T.A. Brown, F. Scala, S.A. Scott, J.S. Dennis, P. Salatino, The attrition behaviour of oxygencarriers under inert and reacting conditions, Chem. Eng. Sci. 71 (2012) 449-467. doi:10.1016/J.CES.2011.11.008.

[4] C. Dueso, M. Ortiz, A. Abad, F. García-Labiano, L.F. de Diego, P. Gayán, J. Adánez, Reduction and oxidation kinetics of nickel-based oxygen-carriers for chemical-looping combustion and 
chemical-looping reforming, Chem. Eng. J. $188 \quad$ (2012) 142-154. doi:10.1016/J.CEJ.2012.01.124.

[5] X. Zhao, H. Zhou, V.S. Sikarwar, M. Zhao, A.-H.A. Park, P.S. Fennell, L. Shen, L.-S. Fan, Biomass-based chemical looping technologies: the good, the bad and the future, Energy Environ. Sci. 10 (2017) 1885-1910. doi:10.1039/C6EE03718F.

[6] P. Cho, T. Mattisson, A. Lyngfelt, Comparison of iron-, nickel-, copper- and manganese-based oxygen carriers for chemical-looping combustion, Fuel. 83 (2004) 1215-1225. doi:10.1016/j.fuel.2003.11.013.

[7] H. Ge, L. Shen, H. Gu, S. Jiang, Effect of co-precipitation and impregnation on K-decorated Fe2O3/A12O3 oxygen carrier in Chemical Looping Combustion of bituminous coal, Chem. Eng. J. 262 (2015) 1065-1076. doi:10.1016/j.cej.2014.10.021.

[8] T.A. Brown, J.S. Dennis, S.A. Scott, J.F. Davidson, A.N. Hayhurst, Gasification and ChemicalLooping Combustion of a Lignite Char in a Fluidized Bed of Iron Oxide, Energy \& Fuels. 24 (2010) 3034-3048. doi:10.1021/ef100068m.

[9] T. Mendiara, J.M. Johansen, R. Utrilla, P. Geraldo, A.D. Jensen, P. Glarborg, Evaluation of different oxygen carriers for biomass tar reforming (I): Carbon deposition in experiments with toluene, Fuel. 90 (2011) 1049-1060. doi:10.1016/j.fuel.2010.11.028.

[10] M. Rydén, P. Moldenhauer, T. Mattisson, A. Lyngfelt, M. Younes, T. Niass, B. Fadhel, J.-P. Ballaguet, Chemical-Looping Combustion with Liquid Fuels, Energy Procedia. 37 (2013) 654661. doi:10.1016/j.egypro.2013.05.153.

[11] T. Mendiara, a. Abad, L.F. de Diego, F. García-Labiano, P. Gayán, J. Adánez, Biomass combustion in a CLC system using an iron ore as an oxygen carrier, Int. J. Greenh. Gas Control. 19 (2013) 322-330. doi:10.1016/j.ijggc.2013.09.012.

[12] H. Gu, L. Shen, J. Xiao, S. Zhang, T. Song, Chemical looping combustion of biomass/coal with natural iron ore as oxygen carrier in a continuous reactor, Energy and Fuels. 25 (2011) 446-455. 
doi:10.1021/ef101318b.

[13] J. Zeng, R. Xiao, H. Zhang, Y. Wang, D. Zeng, Z. Ma, Chemical looping pyrolysis-gasification of biomass for high H2/CO syngas production, Fuel Process. Technol. 168 (2017) 116-122. doi:10.1016/j.fuproc.2017.08.036.

[14] Y. Shen, K. Yoshikawa, Recent progresses in catalytic tar elimination during biomass gasification or pyrolysis-A review, Renew. Sustain. Energy Rev. 21 (2013) 371-392. doi:10.1016/J.RSER.2012.12.062.

[15] A. Sarvaramini, F. Larachi, Integrated biomass torrefaction - Chemical looping combustion as a method to recover torrefaction volatiles energy, Fuel. 116 (2014) 158-167. doi:10.1016/J.FUEL.2013.07.119.

[16] M. Xu, R.C. Brown, G. Norton, J. Smeenk, Comparison of a solvent-free tar quantification method to the International Energy Agency's tar measurement protocol, Energy and Fuels. 19 (2005) 2509-2513. doi:10.1021/ef0501703.

[17] T.A. Milne, R.J. Evans, N. Abatzaglou, Biomass Gasifier “"Tars"”: Their Nature, Formation, and Conversion, 1998. doi:10.2172/3726.

[18] S.M. Nunes, N. Paterson, A.A. Herod, D.R. Dugwell, R. Kandiyoti, Tar formation and destruction in a fixed bed reactor simulating downdraft gasification: Optimization of conditions, Energy and Fuels. 22 (2008) 1955-1964. doi:10.1021/ef700662g.

[19] J.-S. Chern, The pyrolysis and devolatisation of coal in a fluidised bed, University of Cambridge, 1997.

[20] T. Mattisson, A. Lyngfelt, H. Leion, Chemical-looping with oxygen uncoupling for combustion of solid fuels, Int. J. Greenh. Gas Control. 3 (2009) 11-19. doi:10.1016/j.ijggc.2008.06.002.

[21] Y. Huang, S. Dai, F. Feng, X. Zhang, Z. Liu, K. Yan, A comparison study of toluene removal by two-stage DBD-catalyst systems loading with $\mathrm{MnOx}, \mathrm{CeMnOx}$, and CoMnOx, Environ. Sci. Pollut. Res. 22 (2015) 19240-19250. doi:10.1007/s11356-015-5121-3. 
[22] J. Karuppiah, E.L. Reddy, P.M.K. Reddy, B. Ramaraju, R. Karvembu, C. Subrahmanyam, Abatement of mixture of volatile organic compounds (VOCs) in a catalytic non-thermal plasma reactor., J. Hazard. Mater. 237-238 (2012) 283-9. doi:10.1016/j.jhazmat.2012.08.040.

[23] S. Sultana, A. Vandenbroucke, C. Leys, N. De Geyter, R. Morent, Abatement of VOCs with Alternate Adsorption and Plasma-Assisted Regeneration: A Review, Catalysts. 5 (2015) 718746. doi:10.3390/catal5020718.

[24] T. Pham Huu, S. Gil, P. Da Costa, A. Giroir-Fendler, A. Khacef, Plasma-catalytic hybrid reactor: Application to methane removal, Catal. Today. 257 (2015) 86-92. doi:10.1016/j.cattod.2015.03.001.

[25] D.P. Haughey, G.S.G. Beveridge, Structural properties of packed beds - A review, Can. J. Chem. Eng. 47 (1969) 130-140. doi:10.1002/cjce.5450470206.

[26] S.C. Reyes, E. Iglesia, Monte carlo simulations of structural properties of packed beds, Chem. Eng. Sci. 46 (1991) 1089-1099. doi:10.1016/0009-2509(91)85102-4.

[27] W. Hu, F. Donat, S.A. Scott, J.S. Dennis, Kinetics of oxygen uncoupling of a copper based oxygen carrier, Appl. Energy. 161 (2016) 92-100. doi:10.1016/j.apenergy.2015.10.006.

[28] K.H. Becker, U. Kogelschatz, K.H. Schoenbach, R.J. Barker, Non-equilibrium air plasmas at atmospheric pressure, 2005. doi:10.1016/0006-291X(79)91191-4.

[29] C.Y. Wen, Y.H. Yu, A generalized method for predicting the minimum fluidization velocity, AIChE J. 12 (1966) 610-612. doi:10.1002/aic.690120343.

[30] O. Karatum, M.A. Deshusses, A comparative study of dilute VOCs treatment in a non-thermal plasma reactor, Chem. Eng. J. 294 (2016) 308-315. doi:10.1016/j.cej.2016.03.002.

[31] A. Baylet, P. Marécot, D. Duprez, X. Jeandel, K. Lombaert, J.M. Tatibouët, Synergetic effect of plasma/catalysis hybrid system for CH4 removal, Appl. Catal. B Environ. 113 (2012) 31-36. doi:10.1016/j.apcatb.2011.10.026. 
[32] Prabier Basu, Biomass Gasification, Pyrolysis and Torrefaction: Practical Design and Theory, Academic Press, 2013.

[33] R.J. Evans, T.A. Milne, Chemistry of Tar Formation and Maturation in the Thermochemical Conversion of Biomass, in: Dev. Thermochem. Biomass Convers., Springer Netherlands, Dordrecht, 1997: pp. 803-816. doi:10.1007/978-94-009-1559-6_64.

[34] R. Luque, J.G. Speight, Gasification for Synthetic Fuel Production, 2015. doi:10.1016/B978-085709-802-3.00001-1.

[35] S. Bhavsar, B. Tackett, G. Veser, Evaluation of iron- and manganese-based mono- and mixedmetallic oxygen carriers for chemical looping combustion, Fuel. 136 (2014) 268-279. doi:10.1016/j.fuel.2014.07.068.

[36] S.K. Haider, G. Azimi, L. Duan, E.J. Anthony, K. Patchigolla, J.E. Oakey, H. Leion, T. Mattisson, A. Lyngfelt, Enhancing properties of iron and manganese ores as oxygen carriers for chemical looping processes by dry impregnation, Appl. Energy. 163 (2016) 41-50. doi:10.1016/j.apenergy.2015.10.142.

[37] F. Donat, W. Hu, S.A. Scott, J.S. Dennis, Characteristics of Copper-based Oxygen Carriers Supported on Calcium Aluminates for Chemical-Looping Combustion with Oxygen Uncoupling (CLOU), Ind. Eng. Chem. Res. 54 (2015) 6713-23. doi:10.1021/acs.iecr.5b01172.

[38] D.K. Shen, S. Gu, The mechanism for thermal decomposition of cellulose and its main products, Bioresour. Technol. 100 (2009) 6496-6504. doi:10.1016/J.BIORTECH.2009.06.095.

[39] S. Nakamura, U. Siriwat, K. Yoshikawa, S. Kitano, Development of Tar Removal Technologies for Biomass Gasification using the By-products, Energy Procedia. 75 (2015) 208-213. doi:10.1016/J.EGYPRO.2015.07.305.

[40] S. Kwon, M. Fan, T.D. Wheelock, Catalytic Oxidation of CO and CH4 as Well as Mixture of $\mathrm{CO}$ and CH4 with Nano and Micro Fe2 O3, Environ. Eng. Sci. 24 (2007) 1065-1071. doi:10.1089/ees.2006.0227. 
[41] S. Chuang, J. Dennis, A. Hayhurst, S. Scott, Development and performance of Cu-based oxygen carriers for chemical-looping combustion, Combust. Flame. 154 (2008) 109-121. doi:10.1016/j.combustflame.2007.10.005.

[42] R.H. Davies, A.T. Dinsdale, J.A. Gisby, J.A.J. Robinson, S.M. Martin, MTDATAthermodynamic and phase equilibrium software from the national physical laboratory, Calphad. 26 (2002) 229-71. doi:10.1016/S0364-5916(02)00036-6. 